\title{
Prediction of Rhizoma Drynariae Targets in the Treatment of Osteoarthritis Based on Network Pharmacology and Experimental Verification
}

\author{
Guang-yao Chen $\left(\mathbb{D},{ }^{1}\right.$ Xiao-yu Liu $\mathbb{D}^{1},{ }^{1}$ Jia-qi Chen $\mathbb{D}^{1},{ }^{1}$ Xin-bo Yu ${ }^{1},{ }^{1}$ Jing Luo $\mathbb{D},{ }^{2,3}$ \\ Ze-ran Yan $\mathbb{D}^{2,3}$ and Qing-wen Tao $\mathbb{D}^{2,3}$ \\ ${ }^{1}$ Beijing University of Chinese Medicine, Beijing 100029, China \\ ${ }^{2}$ Department of TCM Rheumatology, China-Japan Friendship Hospital, Beijing 100029, China \\ ${ }^{3}$ Beijing Key Lab for Immune-Mediated Inflammatory Diseases, China-Japan Friendship Hospital, Beijing 100029, China
}

Correspondence should be addressed to Qing-wen Tao; taoqg1@outlook.com

Received 7 May 2021; Revised 5 October 2021; Accepted 25 October 2021; Published 18 November 2021

Academic Editor: Nguyen Phuoc Long

Copyright (c) 2021 Guang-yao Chen et al. This is an open access article distributed under the Creative Commons Attribution License, which permits unrestricted use, distribution, and reproduction in any medium, provided the original work is properly cited.

\begin{abstract}
Rhizoma Drynariae has been widely used for the treatment of osteoarthritis (OA), but its potential targets and molecular mechanisms remain to be further explored. Targets of Rhizoma Drynariae and OA were predicted by relevant databases, and a protein-protein interaction (PPI) network was constructed to identify key targets. The Kyoto Encyclopedia of Genes and Genomes (KEGG) enrichment analysis was performed to obtain related pathways and then select significant pathways associated with OA. The OA chondrocyte model was established by inflammatory factor-induced SW1353 chondrocytes, and molecular docking was conducted to verify the above theoretical prediction. The results showed that a total of 86 Rhizoma Drynariae-OA interaction targets were identified, among which IL-6 and AKT1 were the key targets in the PPI network. Luteolin was the most critical component of Rhizoma Drynariae. KEGG results indicated that the effects of Rhizoma Drynariae on OA are associated with the PI3K/AKT, TNF, IL-17, apoptosis, and HIF-1 signaling pathway. The PI3K/AKT pathway can activate the downstream NF- $\kappa \mathrm{B}$ pathway and further regulate the transcription and expression of downstream IL-6, IL-17, HIF-1 $\alpha$, Bax, and TNF, suggesting that the PI3K/AKT/NF- $\kappa$ B pathway is the critical pathway in the treatment of OA with Rhizoma Drynariae. Active components of Rhizoma Drynariae and key proteins of the PI3K/AKT/NF- $\kappa$ B signaling pathway were subjected to molecular docking, whose results showed that luteolin and IKK- $\alpha$ played a critical role. In vitro experiments indicated that both aqueous extracts of Rhizoma Drynariae (AERD) and luteolin inhibited the expression of IL-6 and HIF- $1 \alpha$ and suppressed the activation of PI3K/AKT/NF- $\kappa$ B, IL-17, and TNF pathways. The measurement of mitochondrial membrane potential $(\Delta \psi \mathrm{m})$ indicated that AERD and luteolin can decrease the LPS-induced early apoptotic cells. Luteolin had a more prominent inhibitory effect than AERD in the abovementioned in vitro experiments. In conclusion, the therapeutic mechanism of Rhizoma Drynariae against OA may be closely related to the inhibition of the PI3K/AKT/NF- $\kappa$ B pathway and downstream pathways, and luteolin plays a vital role in the treatment.
\end{abstract}

\section{Introduction}

Osteoarthritis (OA) is the most common joint degenerative disease and the leading cause of disability in elderly people [1]. An imaging study showed that OA affected more than $50 \%$ of elderly individuals [2]. Nonsteroidal anti-inflammatory drugs (NSAIDs) are often prescribed to relieve pain and inflammation that result from OA, but their long-term use may lead to serious gastrointestinal side effects [3]. Glucosamine and chondroitin sulfate show significant chondroprotective effects in in vitro experiments; however, its clinical benefits in OA remain controversial $[4,5]$. As there is no effective and safe pharmacotherapy for treating $\mathrm{OA}$, the search for disease-modifying osteoarthritis drugs 
(DMOADs) from natural sources has received much attention [6]. Rhizoma Drynariae is the root of Drymotaenium fortunei (Kze.) J. Smith and has been used in traditional Chinese medicine for a long time to treat rheumatic diseases [7]. Rhizoma Drynariae is the principal drug in a vast number of TCM prescriptions that have been recognized as effective in treating OA [8]. However, the specific mechanism of Rhizoma Drynariae in treating OA remains to be further investigated.

Network pharmacology aims to identify biological networks and analyze the links among drugs, targets, and diseases in the networks [9]. Network pharmacology assists researchers to identify the key components of complex natural drug ingredients and explore their potential therapeutic mechanisms [10]. In this study, network pharmacology was used to predict the key targets of Rhizoma Drynariae that play an important role in OA, and the Kyoto Encyclopedia of Genes and Genomes (KEGG) pathway enrichment was used to predict the critical mechanisms. Subsequently, these mechanisms were ultimately verified through in vitro experiments and molecular docking. A brief flowchart of the method is shown in Figure 1.

\section{Materials and Methods}

2.1. Collection of Active Compounds and Putative Targets. The compounds in Rhizoma Drynariae were identified from the traditional Chinese medicines for systems pharmacology database and analysis platform (TCMSP, http://lsp.nwu.edu. $\mathrm{cn} / \mathrm{tcmsp}$.php). Oral bioavailability (OB) and drug-likeness (DL) scores were set as the parameters for screening the active compounds, and $\mathrm{OB} \geq 30 \%$ and $\mathrm{OL} \geq 0.18$ were the criteria for the next step. All the putative targets in Rhizoma Drynariae were also identified by the TCMSP database, and targets related to the active components of Rhizoma Drynariae were chosen for further research.

2.2. Collection of OA-Related Targets. The GeneCards database (https://www.genecards.org/), a comprehensive database of human genes, was used for collecting OA-related targets. All the related genes were identified by using "osteoarthritis" as the keyword. The intersecting genes of OA and Rhizoma Drynariae were plotted as a Venn diagram, which was reserved for further study.

2.3. Construction of the Protein-Protein Interaction (PPI) Network. To explore the interaction network of the target proteins and further identify the core regulatory targets, the common targets between OA and Rhizoma Drynariae were analyzed by the PPI network using the STRING database (https://string-db.org/Version 11.0). The parameters were set as follows: organism: Homo sapiens; active interaction sources: text mining, experiments, databases, coexpression, neighborhood, gene fusion, and co-occurrence. Only the interaction score that reached greater than 0.7 was further analyzed. Cytoscape software (version 3.7.1) was used for network visualization, and a bar graph was generated to show the top 30 genes that had the maximum number of connected genes on the network.

2.4. Construction of the Compound-Target Network. Cytoscape software was used to visualize and analyze molecular interactions. The active compounds and intersection genes of Rhizoma Drynariae and OA were loaded into Cytoscape to construct the compound-target network for subsequent analysis.

2.5. KEGG Enrichment Analysis. KEGG was used to analyze which signaling pathways the intersection genes of Rhizoma Drynariae and OA were associated within this study. The clusterProfiler package in $\mathrm{R}$ Studio was used for KEGG analysis. Pathways satisfying $p<0.05$ were considered as significant. The significant pathways were further selected to identify critical pathways associated with OA in accordance with previous literature.

2.6. Molecular Docking of Active Compound and Key Target. Molecular docking is a program for demonstrating the binding affinities between ligands and the active sites of target proteins. In this study, the molecular structures of the ligand and the target protein were downloaded from the ZINC database (https://zinc.docking.org/) and PubChem database (https://pubchem.ncbi.nlm.nih.gov/), respectively. All receptors and ligands were prepared using AutoDockTools (version 1.5.6). The three-dimensional structures of ligands were imported into AutoDockTools to identify their rotatable bonds and then saved in PDB format. The binding sites on all receptors were defined and saved in GPF format. Finally, docking simulations were conducted via Autodock Vina to generate the docking energy. The heat map was generated according to docking energy. The docked complexes were visualized with PyMOL software.

\subsection{Experimental Verification In Vitro}

2.7.1. Reagents and Antibodies. The reagents and antibodies used in this study included the following: SYBR Green real-time PCR master mix (QPK-201, Toyobo, Japan), $0.25 \%$ trypsin-EDTA (Gibco, USA), penicillinstreptomycin (Gibco, USA), fetal bovine serum (ScienCell, USA), Leibovitz's L-15 medium (Gibco, USA), interleukin-1 $\beta$ (IL-1 $\beta$ ) (Peprotech, USA), lipopolysacc haride (LPS) (Sigma, USA), interleukin-17A (IL-17A) (Peprotech, USA), tumor necrosis factor alpha (TNF- $\alpha$ ) (Peprotech, USA), phosphate-buffered saline (PBS, HyClone, USA), MTS (Promega, USA), RIPA lysis buffer (Solarbio Life Sciences, China), phenylmethanesulfonyl fluoride (PMSF) (Solarbio Life Sciences, China), IL-6 enzyme-linked immunosorbent assay (ELISA) kits (Beijing 4A Biotech, China), polymerase chain reaction (PCR) primers for human IL-6 and $\beta$-actin (Tingke, China, primer sequences are listed in Table 1), AKT antibody (ab8805, Abcam, UK), p-AKT (S473) antibody (4060S, Cell Signaling, USA), NF- $\kappa$ B p65 antibody 


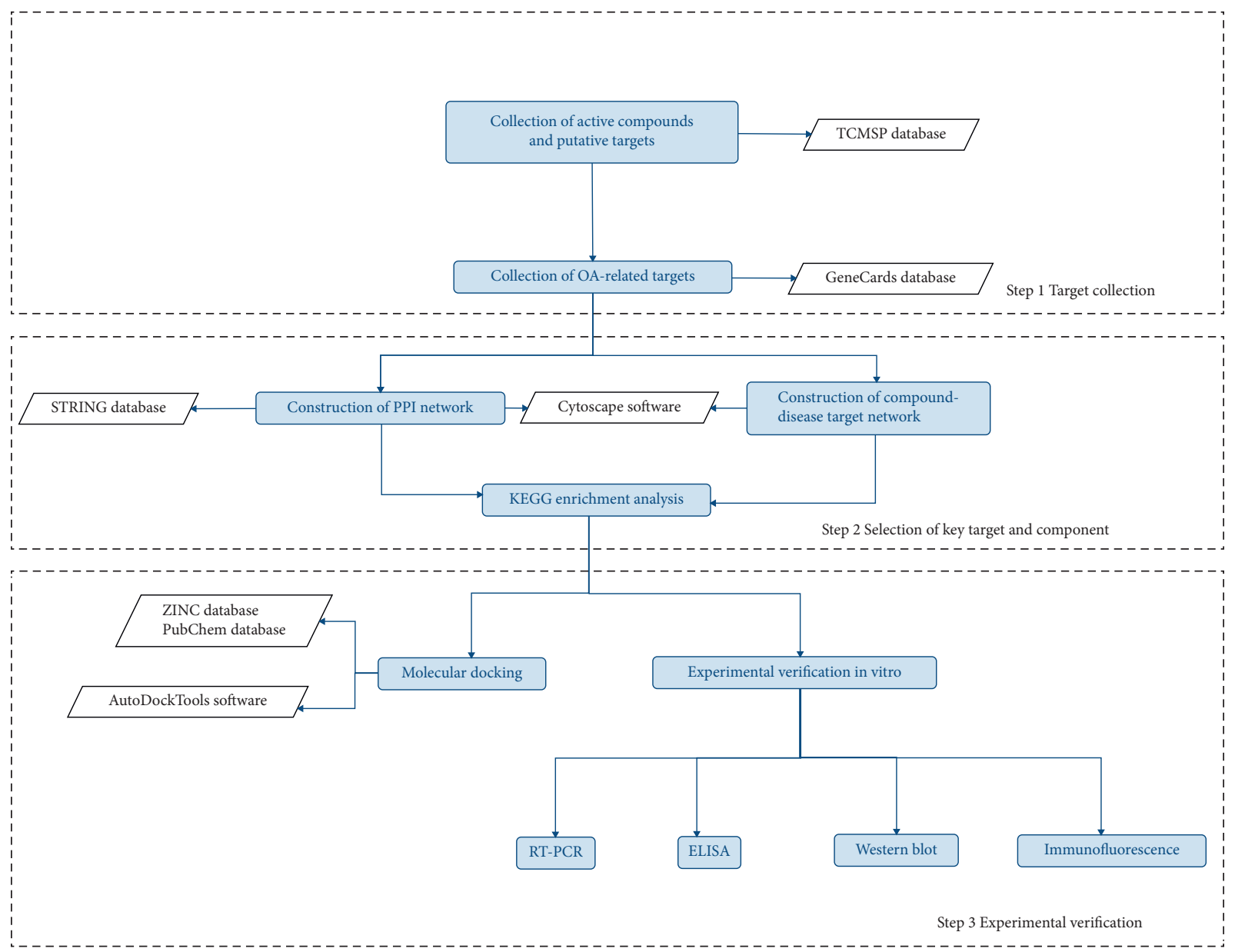

FIGURE 1: Flowchart of the network pharmacology analysis and experimental validation in this study.

Table 1: Prime sequences for real-time PCR.

Gene name

Human IL-6 sense

Human IL-6 antisense

Human HIF- $1 \alpha$ sense

Human HIF- $1 \alpha$

antisense

Human $\beta$-actin sense

Human $\beta$-actin

antisense

IL-6, interleukin-6.

(8242T, Cell Signaling, USA), I $\kappa$ B- $\alpha$ antibody (4814T, Cell Signaling, USA), Lamin B1 antibody (YT5108, Immunoway, USA), $\beta$-Actin antibody (TA-09, Zhongshan Jingqiao Biotechnology, China), horseradish peroxidase (HRP) conjugated goat anti-mouse IgG (ZB5305, Zhongshan Jingqiao Biotechnology, China), HRPconjugated goat anti-rabbit IgG (ZB-2301, Zhongshan Jingqiao Biotechnology, China), and Alexa Fluor 488conjugated goat anti-rabbit IgG $(\mathrm{H}+L)$ (ZF-0511, Zhongshan Jingqiao Biotechnology, China). The following kits were used: nuclear extraction kit (SN0020, Solarbio Life Sciences, China) and mitochondrial membrane potential detection JC-1 kit (551302, BD, USA).

2.7.2. Preparation of Drugs. The aqueous extract of Rhizoma Drynariae (AERD) was purchased from Shanghai Yuanye Bio-Technology Co., Ltd, China. AERD extraction was prepared based on the following protocol: the dried root of Drymotaenium fortunei (Kze.) J. Smith was cut into small pieces, decocted with distilled water three times, and then filtered. The filtered solution was concentrated and vacuumdried to obtain AERD. Luteolin was purchased from Chengdu Herbpurify Co., Ltd, China. AERD was dissolved in PBS, and luteolin was dissolved in DMSO. Syringe filters $(0.22 \mu \mathrm{m})$ were used to filter the drug solutions to ensure sterility before use.

2.7.3. Liquid Chromatography-Mass Spectrometry. The active compounds of AERD selected from TCMSP were identified by liquid chromatography-mass spectrometry (LC-MS). $20 \mathrm{mg}$ of AERD was dissolved with $1 \mathrm{~mL}$ of deionized water and sonicated for $30 \mathrm{~min}$. After centrifugation $(12600 \mathrm{~g} / \mathrm{min}, 10 \mathrm{~min})$, the supernatant was filtered with a microporous membrane $(0.45 \mu \mathrm{m})$. The sample was then measured by ultrahigh performance liquid 
chromatography (UHPLC) (Shimadzu, Japan) coupled with a SCIEX tripleTOF 5600+ mass spectrometer. The results were compared with the MassBank online Spectral Database (https://massbank.eu/MassBank/), ReSpect DB (http:// spectra.psc.riken.jp), and GNPS platform (https://gnps. ucsd.edu/).

2.7.4. Experimental Validation. The specific methods of the validation experiments, including cell culture, MTS assay, RNA isolation, PCR, ELISA, western blotting, and immunofluorescence, are shown in our previous research [11]. The mitochondrial membrane potential $(\Delta \psi \mathrm{m})$ was measured by flow cytometry (BD FACSCanto II, USA) using the mitochondrial membrane potential detection JC-1 kit according to the manufacturer's instructions.

2.7.5. Statistical Analysis. Continuous variables are presented as mean \pm standard deviation (SDs). Student's $t$-test was used to evaluate the differences between the two groups, and $p<0.05$ was considered to indicate a statistically significant difference.

\section{Results}

3.1. Active Compounds and Targets of Rhizoma Drynariae. A total of 71 active compounds were identified in Rhizoma Drynariae by the TCMSP database, among which 18 satisfied the criteria of $\mathrm{OB} \geq 30 \%$ and $\mathrm{OL} \geq 0.18$, and the results of LCMS showed that all the 18 active components were identified in AERD (Figure 2), and the chemical identification of each component was shown in Table 2. A total of 139 putative targets corresponding to the 18 active compounds were retrieved from the TCMSP database (Supplementary Table 1).

3.2. OA-Related Targets. A total of $3143 \mathrm{OA}$-related targets were identified in the GeneCards database, of which 86 targets were associated with Rhizoma Drynariae. Detailed information on OA-related targets was provided in Supplementary Table 2. The Venn diagram was generated to demonstrate the number of Rhizoma Drynariae-OA interaction targets (Figure 3 ).

3.3. PPI Network. The interactions between the 86 Rhizoma Drynariae-OA interaction targets were used to construct the PPI network and visualized by Cytoscape (Figure 4(a)). The results showed that AKT1, JUN, CASP3, and IL-6 had the most relative connections with other genes, indicating that they were the most critical gene targets in this network. IL-6 is a vital end product of multiple inflammatory signaling pathways, and therefore, it is selected as an indicator to determine the curative efficacy of the drugs. Other hub genes included JUN, CASP3, MAPK3, PTGS2, EGFR, VEGFA, MMP9, RELA, and BCL2L1 (Figure 4(b)).

3.4. Compound-Target Network. The compound-target network was built and visualized in accordance with active compounds and Rhizoma Drynariae-OA interaction targets (Figure 5). The results suggested that 14 of the 18 active compounds, including luteolin, kaempferol, naringenin, beta-sitosterol, and aureusidin, were involved in the network. Among the abovementioned, luteolin had a maximum of 41 connections with Rhizoma Drynariae-OA interaction targets, suggesting that luteolin played a central role in the effects of Rhizoma Drynariae in the treatment of OA.

3.5. KEGG Enrichment Analysis. 86 Rhizoma Drynariae-OA interaction targets were subjected to the KEGG enrichment analysis. Pathways satisfying $p<0.05$ were considered statistically important, and the top 20 pathways were visualized by a dot plot (Figure 6). The combination of the KEGG enrichment results and systematical literature identified the OA-related pathways, including the PI3K/AKT pathway [12], TNF pathway [13], IL-17 pathway [14], apoptosis pathway [15], and HIF-1 pathway [16]. The PI3K/AKT pathway has the maximum connections with Rhizoma Drynariae-OA interaction targets, and it can also activate the NF- $\kappa \mathrm{B}$ pathway to enhance the transcription of TNF- $\alpha$, IL17 , Bax, and HIF- $1 \alpha$ and thereby regulate the activation of the TNF pathway, IL-17 pathway, apoptosis pathway, and HIF-1 pathway [17-20]. Therefore, the PI3K/AKT/NF- $\kappa \mathrm{B}$ pathway was selected for further experimental verification and molecular docking.

3.6. Molecular Docking of Active Compound and Key Target. Molecular docking was conducted to predict the binding energy between the active compounds involved in the C-T network and key proteins of the $\mathrm{PI} 3 \mathrm{~K} / \mathrm{AKT} / \mathrm{NF}-\kappa \mathrm{B}$ pathway (PI3K, AKT1, IKK- $\alpha$, IKK- $\beta$, and IKB- $\alpha / \mathrm{p} 65$ ), whose results were visualized by a heat map (Figure $7(\mathrm{a})$ ). Luteolin has larger binding energy with key proteins relative to the rest of the active compounds, which confirms that luteolin may be a key compound in the treatment of OA with Rhizoma Drynariae. Luteolin has the maximum binding energy with IKK- $\alpha(-9.20 \mathrm{kcal} / \mathrm{mol})$, which may play a significant role in the effect of luteolin on the PI3K/AKT/NF- $\kappa \mathrm{B}$ pathway. The docking site of luteolin and $\mathrm{IKK}-\alpha$ is visualized in Figure 7(b).

3.7. Effects of AERD and Luteolin on SW1353 Cell Viability. To determine the appropriate treatment concentration for SW1353 cells, the cells were treated with different concentrations of AERD or luteolin for $12 \mathrm{~h}$, with or without $10 \mathrm{ng} / \mathrm{mL} \mathrm{IL-1} \beta$. The MTS assay results indicated that compared with that of the control group, $2000 \mathrm{mg} / \mathrm{L}$ AERD promoted cell viability, $2500 \mathrm{mg} / \mathrm{L}$ AERD exhibited no effect on cell viability, and $3000 \mathrm{mg} / \mathrm{L}$ AERD significantly inhibited cell proliferation. Luteolin had no significant effect on cell proliferation at concentrations of $5 \mu \mathrm{mol} / \mathrm{L}, 10 \mu \mathrm{mol} / \mathrm{L}, 15 \mu \mathrm{mol} / \mathrm{L}, 20 \mu \mathrm{mol} / \mathrm{L}, 25 \mu \mathrm{mol} / \mathrm{L}$, and $30 \mu \mathrm{mol} / \mathrm{L}$, but cell viability was inhibited at a concentration of $35 \mu \mathrm{mol} / \mathrm{L}$ (Figure 8). Treatment with $10 \mathrm{ng} /$ $\mathrm{mL}$ IL- $1 \beta$ had no effect on cell viability with different concentrations of AERD and luteolin. Therefore, 


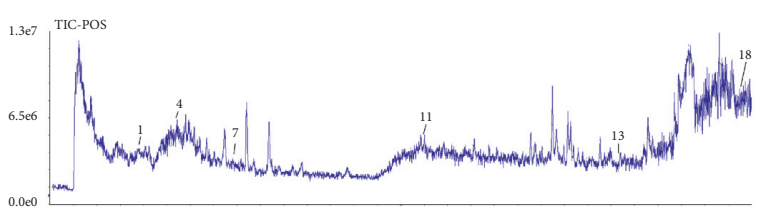

(a)

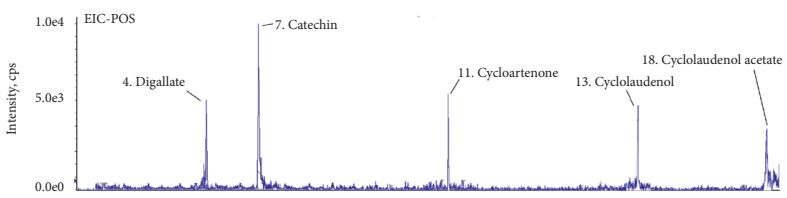

(c)

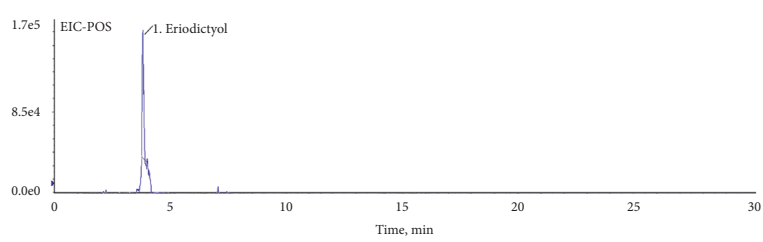

(e)

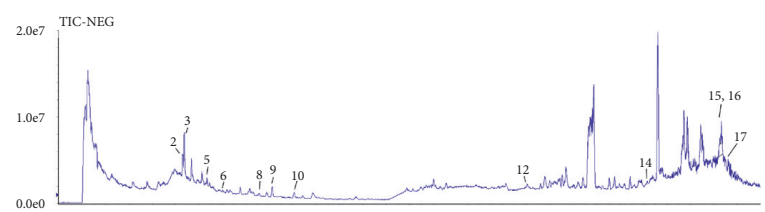

(b)

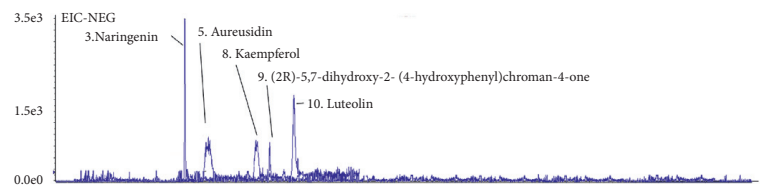

(d)

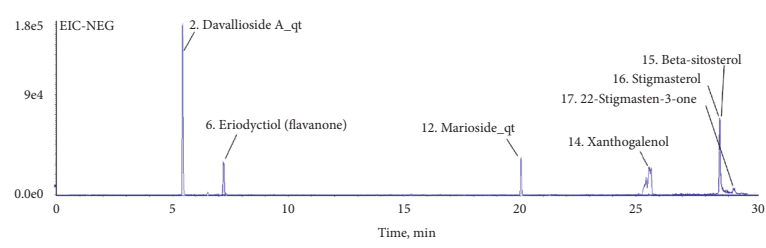

(f)

FIGURE 2: Total ion chromatography (TIC) on positive (a) and negative (b) and extraction ion chromatography (EIC, C-F) of the aqueous extract of Rhizoma Drynariae (AERD).

TAble 2: Chemical identification of Drynariae Rhizoma active compounds predicted by TCMSP.

\begin{tabular}{|c|c|c|c|c|c|c|c|c|c|c|c|}
\hline No & $\begin{array}{c}\mathrm{RT} \\
(\mathrm{min}) \\
\end{array}$ & Mol. ID & Name & Formula & OB (\%) & $\mathrm{DL}$ & Ion & Cal. $(\mathrm{m} / \mathrm{z})$ & Mea. (m/z) & Error (ppm) & MS/MS \\
\hline 1 & 3.82 & MOL005190 & Eriodictyol & $\mathrm{C}_{15} \mathrm{H}_{12} \mathrm{O}_{6}$ & 71.79 & 0.24 & $\mathrm{M}+\mathrm{H}$ & 289.0706 & 289.0711 & 1.506 & $\begin{array}{l}289.0711 \\
185.0035\end{array}$ \\
\hline 2 & 5.39 & MOL009078 & $\begin{array}{c}\text { Davallioside } \\
\text { A_qt }\end{array}$ & $\mathrm{C}_{19} \mathrm{H}_{19} \mathrm{NO}_{7}$ & 62.65 & 0.51 & M-H & 372.1088 & 372.1090 & 3.283 & $\begin{array}{c}372.1088, \\
164.0430,120.0548\end{array}$ \\
\hline 3 & 5.57 & MOL004328 & Naringenin & $\mathrm{C}_{15} \mathrm{H}_{12} \mathrm{O}_{5}$ & 59.29 & 0.21 & $\mathrm{M}-\mathrm{H}$ & 271.0611 & 271.0609 & 2.95 & $271.0609,185.0033$ \\
\hline 4 & 5.59 & MOL000569 & Digallate & $\mathrm{C}_{14} \mathrm{H}_{10} \mathrm{O}_{9}$ & 61.85 & 0.26 & $\mathrm{M}+\mathrm{H}$ & 323.0397 & 323.0386 & -3.586 & 323.0386 \\
\hline 5 & 6.60 & MOL001978 & Aureusidin & $\mathrm{C}_{15} \mathrm{H}_{10} \mathrm{O}_{6}$ & 53.42 & 0.24 & M-H & 285.0404 & 285.04 & 2.23 & 285.04,224.9613, \\
\hline 6 & 7.21 & MOL002914 & $\begin{array}{l}\text { Eriodictyol } \\
\text { (flavanone) }\end{array}$ & $\mathrm{C}_{15} \mathrm{H}_{12} \mathrm{O}_{2}$ & 41.35 & 0.24 & M-H & 223.0764 & 223.076 & 2.886 & $\begin{array}{c}223.076,109.0276 \\
57.0392\end{array}$ \\
\hline 7 & 7.91 & MOL000492 & Catechin & $\mathrm{C}_{15} \mathrm{H}_{14} \mathrm{O}_{6}$ & 54.83 & 0.24 & $\mathrm{M}+\mathrm{H}$ & 291.0863 & 291.0861 & -0.737 & $\begin{array}{l}291.0861 \\
109.0012\end{array}$ \\
\hline 8 & 8.66 & MOL000422 & $\begin{array}{l}\text { Kaempferol } \\
(2 \mathrm{R})-5,7- \\
\text { dihydroxy-2- }\end{array}$ & $\mathrm{C}_{15} \mathrm{H}_{10} \mathrm{O}_{6}$ & 41.88 & 0.24 & $\mathrm{M}-\mathrm{H}$ & 285.0404 & 285.0403 & 3.282 & $228.9613,185.0038$ \\
\hline 9 & 9.23 & MOL001040 & $\begin{array}{l}\text { (4- } \\
\text { hydroxyphenyl) } \\
\text { chroman-4-one }\end{array}$ & $\mathrm{C}_{15} \mathrm{H}_{12} \mathrm{O}_{5}$ & 42.36 & 0.21 & $\mathrm{M}-\mathrm{H}$ & 271.0611 & 271.061 & 3.32 & $271.061,185.0026$ \\
\hline 10 & 10.26 & MOL000006 & Luteolin & $\mathrm{C}_{15} \mathrm{H}_{10} \mathrm{O}_{6}$ & 36.16 & 0.25 & M-H & 285.0404 & 285.0401 & 2.58 & $285.0401,185.0138$ \\
\hline 11 & 15.87 & MOL009075 & Cycloartenone & $\mathrm{C}_{30} \mathrm{H}_{48} \mathrm{O}$ & 40.57 & 0.79 & $\mathrm{M}+\mathrm{H}$ & 425.3778 & 425.3781 & 0.722 & 425.3781 \\
\hline 12 & 20.37 & MOL009087 & Marioside_qt & $\mathrm{C}_{16} \mathrm{H}_{24} \mathrm{O}_{5}$ & 70.79 & 0.19 & $\mathrm{M}-\mathrm{H}$ & 295.1551 & 295.155 & 3.387 & $295.155,164.0452$ \\
\hline 13 & 23.99 & MOL009076 & Cyclolaudenol & $\mathrm{C}_{31} \mathrm{H}_{52} \mathrm{O}$ & 39.05 & 0.79 & $\mathrm{M}+\mathrm{H}$ & 441.409 & 441.4088 & -2.131 & 441.4088 \\
\hline 14 & 25.34 & MOL009091 & Xanthogalenol & $\mathrm{C}_{21} \mathrm{H}_{22} \mathrm{O}_{5}$ & 41.08 & 0.32 & $\mathrm{M}-\mathrm{H}$ & 353.1394 & 353.139 & 1.840 & $353.1394,191.0571$ \\
\hline 15 & 28.62 & MOL000358 & Beta-sitosterol & $\mathrm{C}_{29} \mathrm{H}_{50} \mathrm{O}$ & 36.91 & 0.75 & M-H & 413.3789 & 413.3782 & 0.985 & 413.3782 \\
\hline 16 & 28.62 & MOL000449 & Stigmasterol & $\mathrm{C}_{29} \mathrm{H}_{48} \mathrm{O}$ & 43.83 & 0.76 & $\mathrm{M}-\mathrm{H}$ & 411.3632 & 411.3629 & 1.841 & 411.3629 \\
\hline 17 & 29.26 & MOL009061 & $\begin{array}{l}\text { 22-Stigmasten- } \\
\text { 3-one }\end{array}$ & $\mathrm{C}_{29} \mathrm{H}_{48} \mathrm{O}$ & 39.25 & 0.76 & $\mathrm{M}-\mathrm{H}$ & 411.3632 & 411.363 & 2.084 & 411.363 \\
\hline 18 & 29.46 & MOL009063 & $\begin{array}{l}\text { Cyclolaudenol } \\
\text { acetate } \\
\end{array}$ & $\mathrm{C}_{33} \mathrm{H}_{54} \mathrm{O}_{2}$ & 41.66 & 0.79 & $\mathrm{M}+\mathrm{H}$ & 483.4197 & 483.4196 & -1.221 & 483.4196 \\
\hline
\end{tabular}

$2500 \mathrm{mg} / \mathrm{L}$ AERD and $30 \mu \mathrm{mol} / \mathrm{L}$ luteolin were selected as the maximum intervention concentrations of SW1353 cells.
3.8. Effects of AERD and Luteolin on IL-6 Expression in IL-1 $\beta$-Treated SW1353 Cells. To detect the effects of AERD and luteolin on IL- 6 expression in IL- $1 \beta$-treated SW1353 


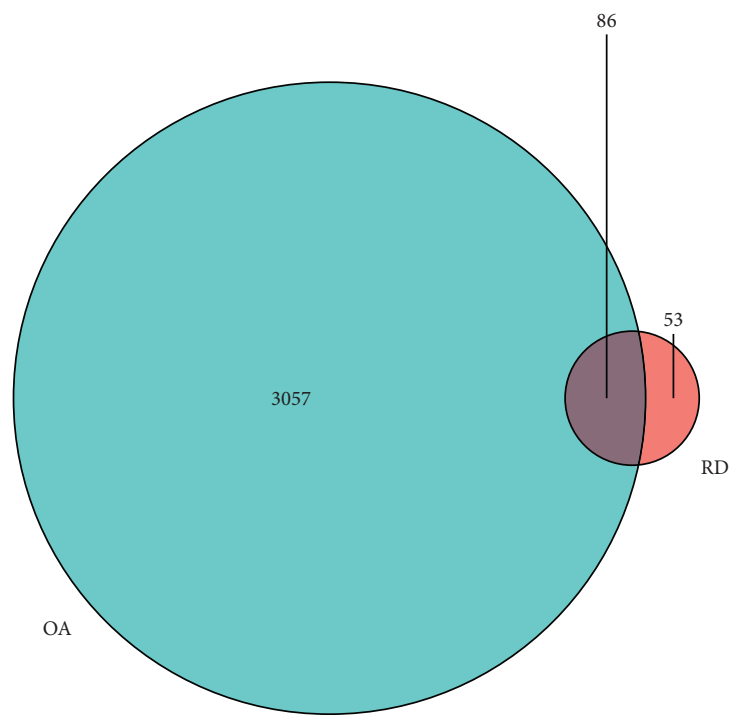

Figure 3: The number of OA-related targets, Rhizoma Drynariae-related targets, and the interaction targets are shown in the Venn diagram.

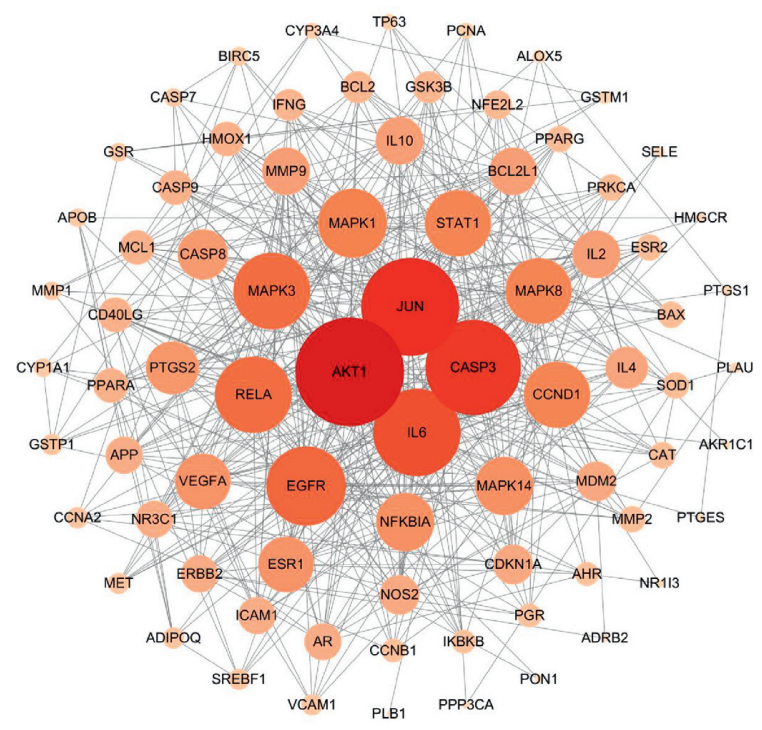

(a)

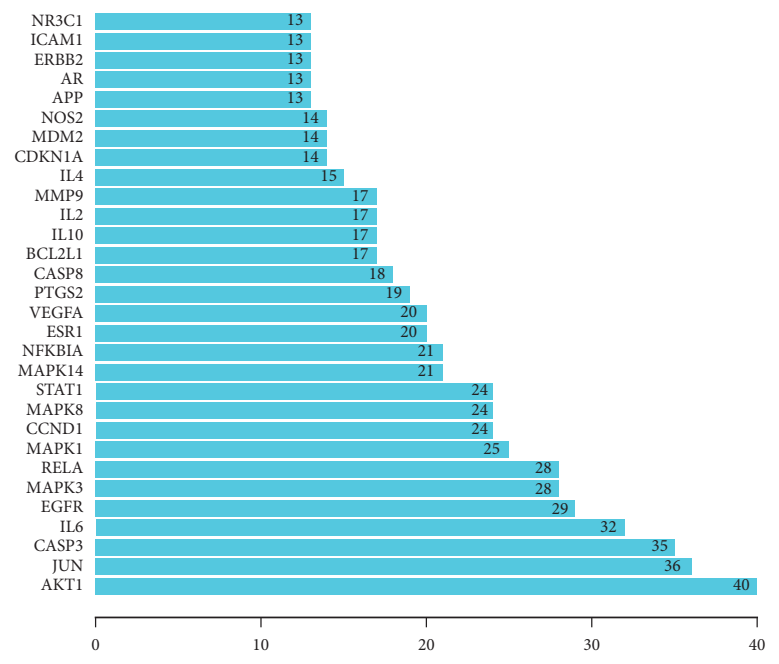

(b)

FIgURe 4: (a) The PPI network of the 86 Rhizoma Drynariae-OA interaction targets. The size indicates the number of connections; the larger the number is, the more connections there are in the network. (b) Barplot of the top 30 Rhizoma Drynariae-OA interaction targets, sorted by target connectivity from large to small in the PPI network.

cells, SW1353 cells were pretreated with $625 \mathrm{mg} / \mathrm{L}, 1250 \mathrm{mg} /$ $\mathrm{L}$, or $2500 \mathrm{mg} / \mathrm{L}$ AERD or $7.5 \mu \mathrm{mol} / \mathrm{L}, 15 \mu \mathrm{mol} / \mathrm{L}$, or $30 \mu \mathrm{mol} / \mathrm{L}$ luteolin for $1 \mathrm{~h}$, and then treated with $10 \mathrm{ng} / \mathrm{mL}$ IL- $1 \beta$ for $12 \mathrm{~h}$. RT-PCR was used to detect mRNA expression, and ELISA was used to detect the protein levels in the supernatant. RT-PCR results indicated that the mRNA expression of SW1353 cells was significantly increased after stimulation with IL-1 $\beta$ (upregulated approximately 500fold). Both AERD and luteolin inhibited mRNA expression and showed dose-dependent effects. However, the highest concentration of luteolin, which can inhibit IL-6 mRNA expression to nearly normal levels (2-fold), was significantly more effective than AERD. The results of ELISA detection of the protein levels in supernatant were consistent with the trends observed by PCR. The results suggested that IL- $1 \beta$ promoted the transcription of IL- 6 in SW1353 cells and led to the increased expression of IL- 6 protein. This response was reversed by AERD and luteolin, and luteolin may be the key component of Rhizoma Drynariae in the treatment of OA (Figure 9).

3.9. Effects of AERD and Luteolin on IL-1 $\beta$-Induced Activation of the PI3K/AKT Pathway. SW1353 cells were pretreated with $2500 \mathrm{mg} / \mathrm{L}$ AERD or $30 \mu \mathrm{mol} / \mathrm{L}$ luteolin for $1 \mathrm{~h}$ and then stimulated with $10 \mathrm{ng} / \mathrm{mL}$ IL- $1 \beta$ for $12 \mathrm{~h}$. The results 


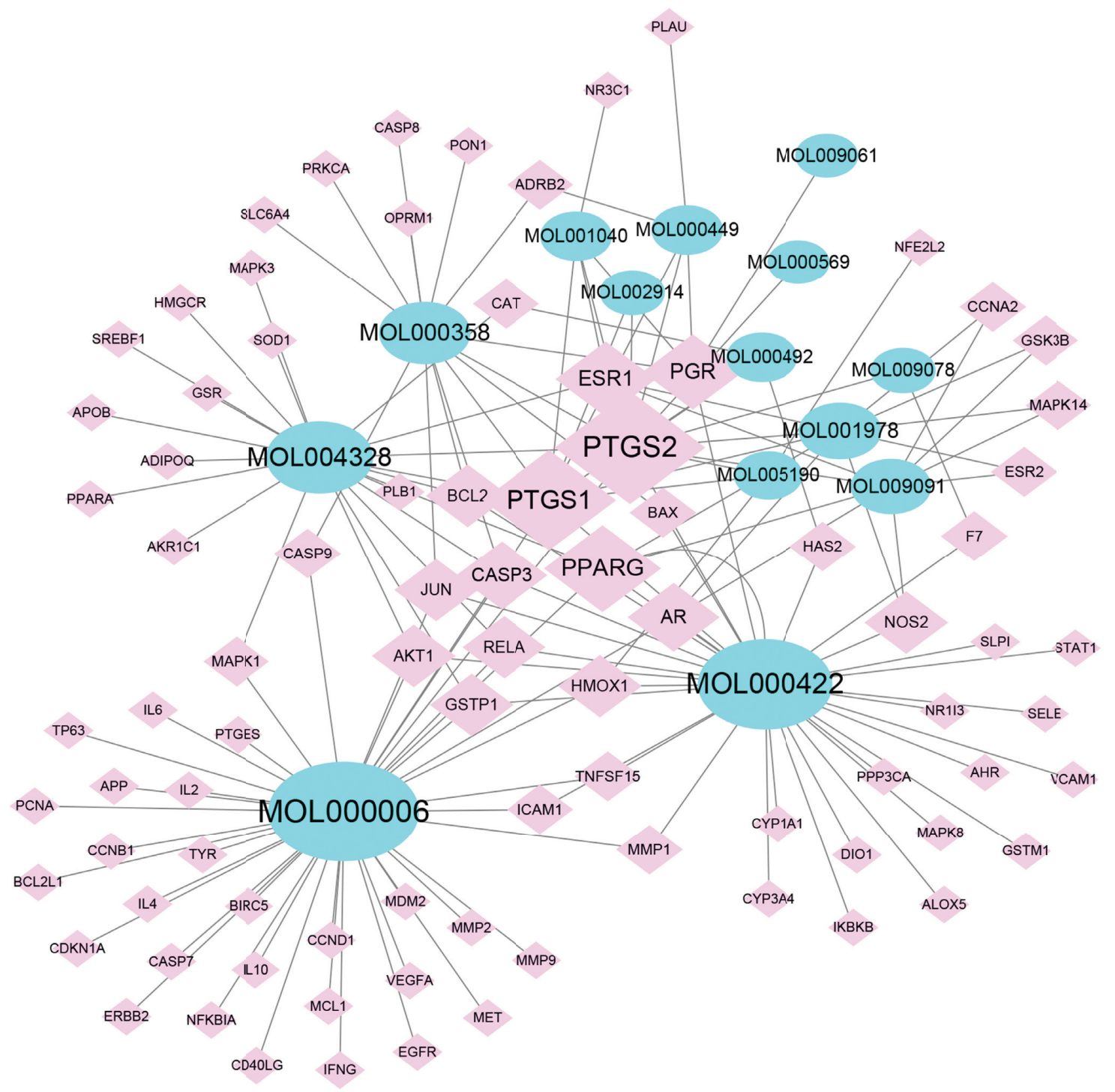

FiguRE 5: The compound-target network of active compounds and Rhizoma Drynariae-OA interaction targets. The blue nodes represent active compounds of Rhizoma Drynariae; the pink nodes represent Rhizoma Drynariae-OA interaction genes. The larger the node is, the more connections the gene or active compound has.

demonstrated that IL-1 $\beta$ did not affect the protein expression of AKT but markedly promoted the phosphorylation of AKT (Ser473). Both AERD and luteolin at the highest concentration inhibited p-AKT expression, and the effect of luteolin was more prominent than that of AERD (Figure 10).

3.10. Effects of AERD and Luteolin on IL-1ß-Induced Activation of the NF- $\kappa B$ Pathway. The PI3K/AKT signaling pathway can activate the NF- $\kappa \mathrm{B}$ signaling pathway by phosphorylating IKK and further lead to IkB- $\alpha$ degradation in the cytoplasm and NF- $\kappa \mathrm{B}$ nuclear translocation. To further determine the effect of AERD and luteolin intervention on the NF- $\kappa$ B signaling pathways, SW1353 cells were pretreated with $2500 \mathrm{mg} / \mathrm{L}$ AERD or $30 \mu \mathrm{mol} / \mathrm{L}$ luteolin for $1 \mathrm{~h}$ and then stimulated with $10 \mathrm{ng} / \mathrm{mL}$ IL- $1 \beta$ for $30 \mathrm{~min}$.
A nuclear extraction kit was used to extract the total cytoplasmic and nuclear proteins from the cells. IkB- $\alpha$ expression in the cytoplasm and NF- $\kappa \mathrm{B}$ P65 expression in the nucleus were determined by western blot, and $\beta$-actin and Lamin B1 were used as cytoplasmic and nuclear internal references, respectively. After stimulation with IL- $1 \beta$, the NF- $\kappa$ B p65 level in the nuclei was increased, and the IkB- $\alpha$ level in the cytoplasm was decreased, which indicated that the NF- $\kappa \mathrm{B}$ signaling pathway was activated. These changes could be reversed by pretreatment with AERD and luteolin, and luteolin had a significant effect (Figure 11).

Cellular localization of NF- $\kappa$ B p 65 can be determined by an immunofluorescence assay. In this study, NF- $\kappa$ B p 65 was significantly transferred from the cytoplasm to the nuclei after being stimulated by $10 \mathrm{ng} / \mathrm{mL}$ IL- $1 \beta$ for $30 \mathrm{~min}$. Results showed that the pretreatment of AERD or luteolin exhibited 


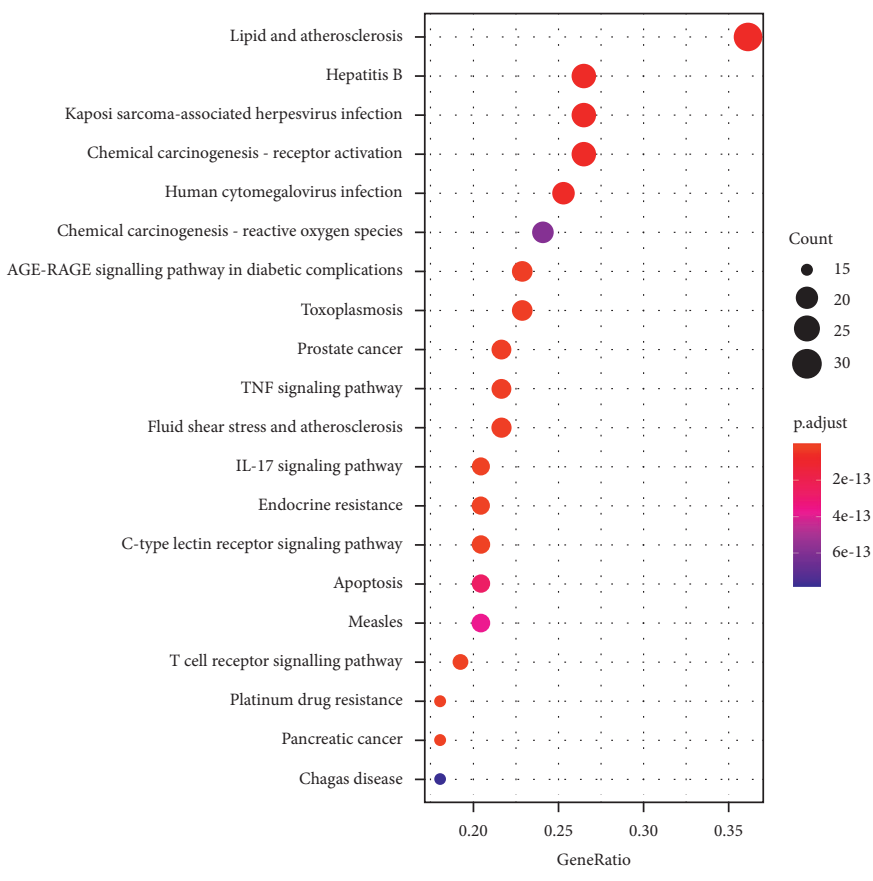

(a)

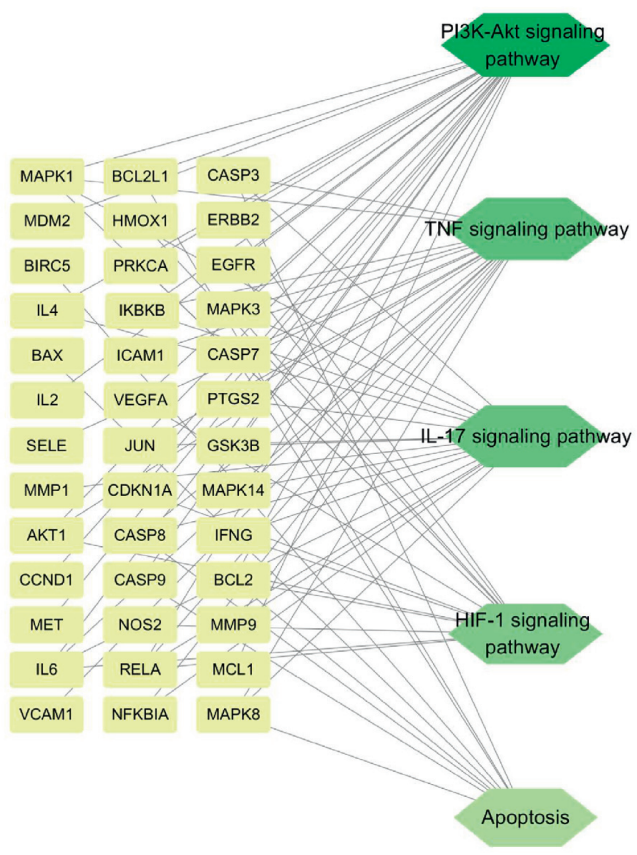

(b)

Figure 6: (a) Dot plot for the top 20 KEGG pathways. The size of nodes represents enriched counts. The colors represent significant pvalues $(p<0.05)$; red represents low $p$ values, and blue represents high pvalues. (b) A network of 5 OA-related pathways identified from KEGG enrichment analysis and their corresponding targets. Hexagons represent pathways, and rectangles represent the corresponding genes.

inhibitory effects on this change to a certain extent, while luteolin had a more remarkable effect (Figure 12).

\subsection{Effects of AERD and Luteolin on LPS-Induced Changes in} the Mitochondrial Membrane Potential $(\Delta \psi m)$. Decreased mitochondrial membrane potential $(\Delta \psi \mathrm{m})$ is considered as a critical hallmark of early cell apoptosis. The mitochondrial membrane potential $(\Delta \psi \mathrm{m})$ was measured with the fluorescent mitochondrial probe JC-1. The cells were pretreated with $2500 \mathrm{mg} / \mathrm{L} \mathrm{AERD}$ or $30 \mu \mathrm{mol} / \mathrm{L}$ luteolin for $1 \mathrm{~h}$ and then stimulated with $4 \mu \mathrm{g} / \mathrm{mL}$ LPS for $24 \mathrm{~h}$. Red/green JC-1 fluorescence correlating with the mitochondrial membrane potential $(\Delta \psi \mathrm{m})$ was measured by flow cytometry (Figure 13). The results of flow cytometric measurement indicated that the stimulation of LPS enhanced the ratio of green JC-1 fluorescence of cells to red JC-1 fluorescence of cells (4.506) compared with that of the control group (1.454), whereas AERD (2.956) and luteolin (2.243) can reverse the changes to a certain extent.

3.12. Effects of AERD and Luteolin on the Inhibition of IL-17 and TNF Signaling Pathways. $10 \mathrm{ng} / \mathrm{mL}$ IL-17A was used to activate the IL-17 signaling pathway, and $10 \mathrm{ng} / \mathrm{mL}$ TNF- $\alpha$ was used to activate the TNF signaling pathway. The SW 1353 cells were pretreated with $2500 \mathrm{mg} / \mathrm{L}$ AERD or $30 \mu \mathrm{mol} / \mathrm{L}$ luteolin for $1 \mathrm{~h}$ and then stimulated with $10 \mathrm{ng} /$
$\mathrm{mL}$ IL-17A or TNF- $\alpha$ for $12 \mathrm{~h}$. The content of IL- 6 in the culture supernatants was determined to reflect the activation extent of the IL-17 and TNF pathways. The results suggested that IL-17A or TNF- $\alpha$ can markedly promote the content of IL- 6 in the culture supernatants, and the increase of IL- 6 was reversed by AERD and luteolin (Figure 14).

3.13. Effects of AERD and Luteolin on mRNA Expression of $H I F-1 \alpha$. The SW1353 cells were pretreated with $2500 \mathrm{mg} / \mathrm{L}$ AERD or $30 \mu \mathrm{mol} / \mathrm{L}$ luteolin for $1 \mathrm{~h}$ and then stimulated with $10 \mathrm{ng} / \mathrm{mL}$ IL- $1 \beta$ for $12 \mathrm{~h}$. The results indicated that the stimulation of IL- $1 \beta$ remarkedly increased mRNA expression of HIF- $1 \alpha$; however, AERD and luteolin can inhibit the IL- $1 \beta$-induced mRNA expression of HIF- $1 \alpha$ and luteolin had a significant effect (Figure 15).

\section{Discusssion}

Network pharmacology was conducted to predict the key targets and therapeutic mechanisms of Rhizoma Drynariae for the treatment of OA, whose results showed that luteolin was the most critical component of Rhizoma Drynariae for OA treatment. KEGG results indicated that the curative effects of Rhizoma Drynariae depend on the PI3K/AKT signaling pathway, TNF pathway, IL-17 pathway, apoptosis pathway, and HIF-1 pathway. 


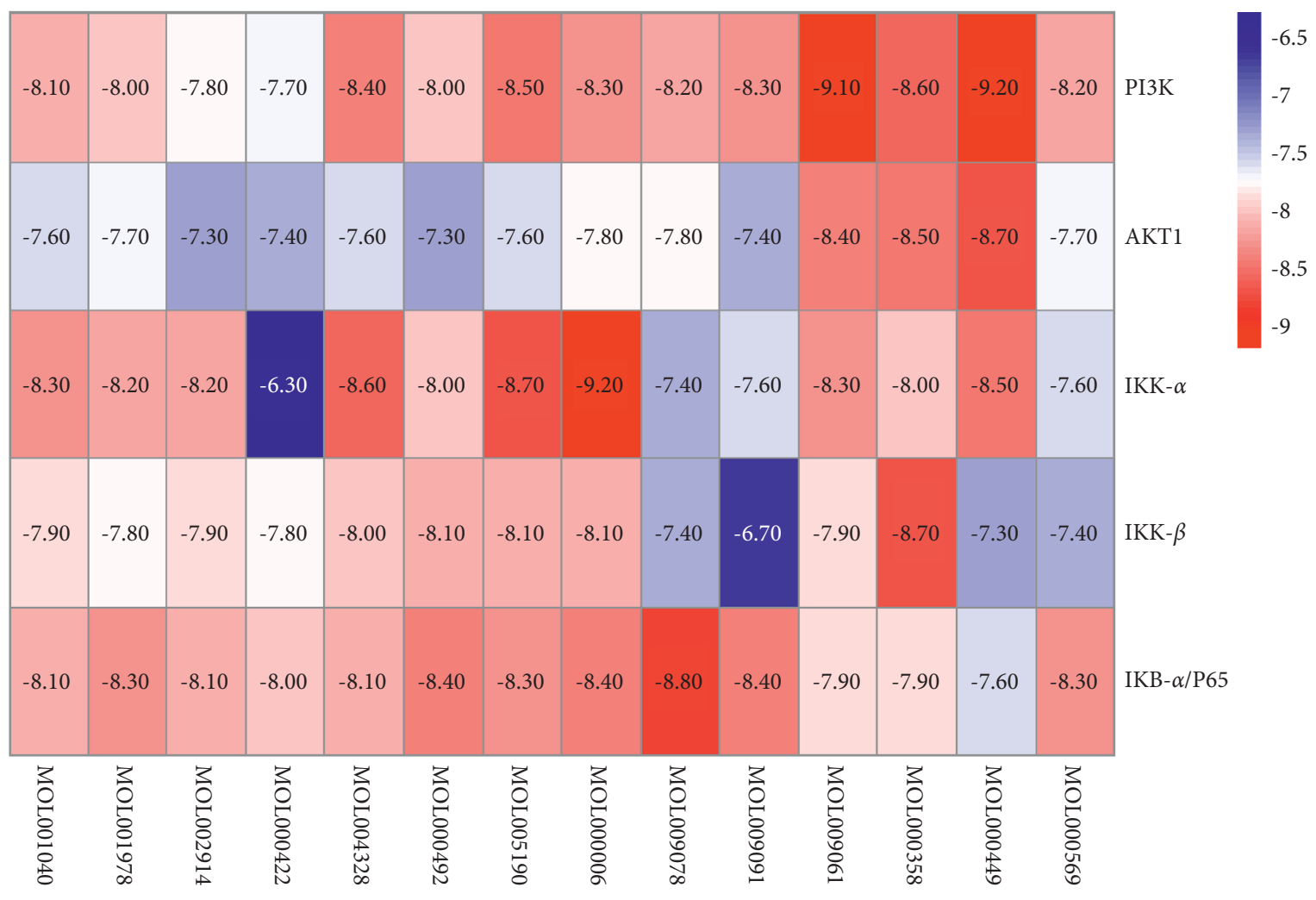

(a)

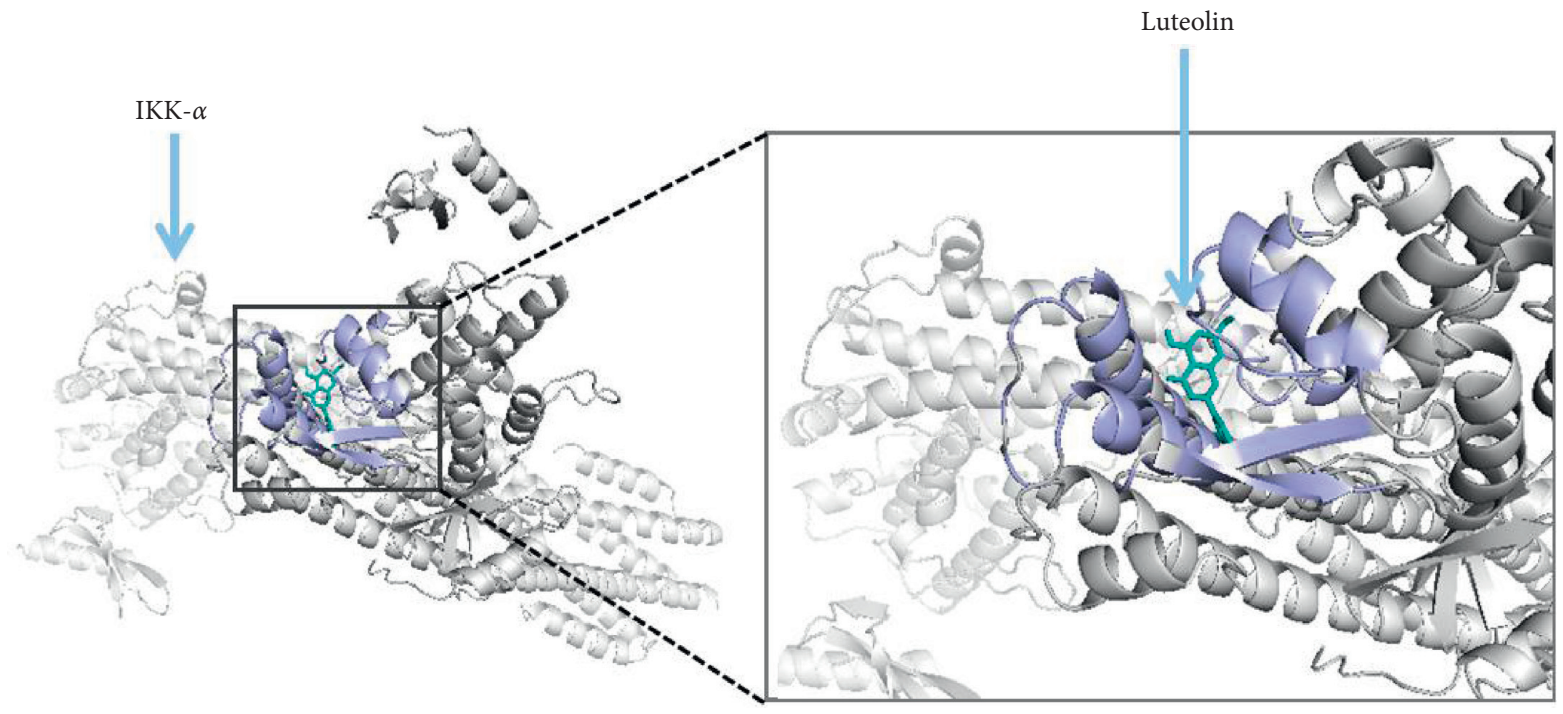

(b)

FIGURE 7: (a) The heat map of binding energy between the active compounds involved in the C-T network and PI3K, AKT1, IKK- $\alpha$, IKK- $\beta$, and IKB- $\alpha /$ p65. (b) Molecular docking site of IKK- $\alpha$ and luteolin.

An increasing number of studies have demonstrated that the low-grade inflammation of chondrocytes is closely associated with the progression of OA, suggesting that inhibition of inflammation in OA could be a promising therapeutic strategy [21]. IL-6 was first cloned in the 1980s and verified to promote the activation of T and B lymphocytes [22]. Subsequent studies have shown that IL- 6 can be produced by various cells of the human body and has a series of functions, such as modulating the immune system [23], hematopoietic system [24], and neuroendocrine system [25]. IL-6 is produced by synoviocytes and chondrocytes in joints and is considered to be a crucial regulator of cartilage inflammation [26]. Studies have shown that the use of specific IL-6 inhibitors can effectively reduce the inflammatory response in OA model rats, indicating that inhibition of IL- 6 is an appealing potential approach in the treatment of OA [27]. 


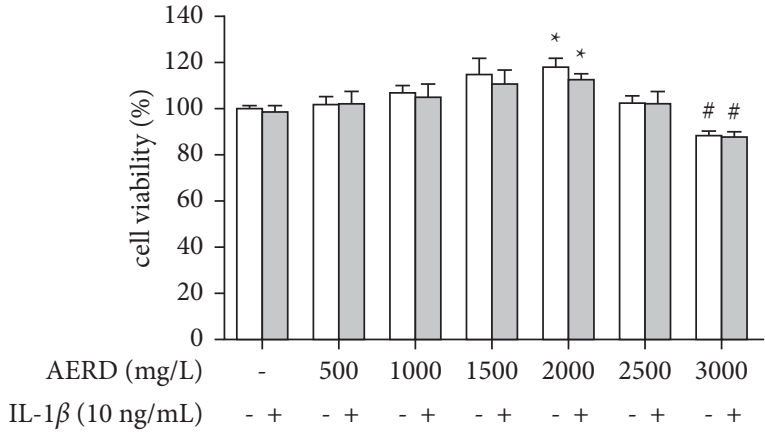

(a)

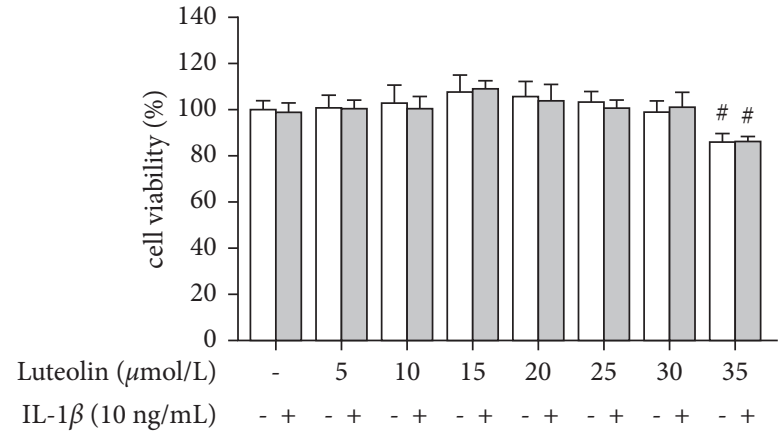

(b)

FIGURE 8: The viability of SW1353 cells after treatment with different concentrations of the aqueous extract of Rhizoma Drynariae (AERD) or luteolin, with or without $10 \mathrm{ng} / \mathrm{mL}$ IL-1 $\beta$. (a) SW 1353 cells were treated with different concentrations of AERD for $12 \mathrm{~h}$ with or without $10 \mathrm{ng} / \mathrm{mL}$ IL-1 $\beta$. (b) SW 1353 cells were treated with different concentrations of luteolin for $12 \mathrm{~h}$ with or without $10 \mathrm{ng} / \mathrm{mL}$ IL- $1 \beta$. The data are derived from three independent experiments and are expressed as mean \pm standard deviation $\left({ }^{*} p<0.05\right.$ : increase compared with the control group; $p<0.05$ : decrease compared with the control group).

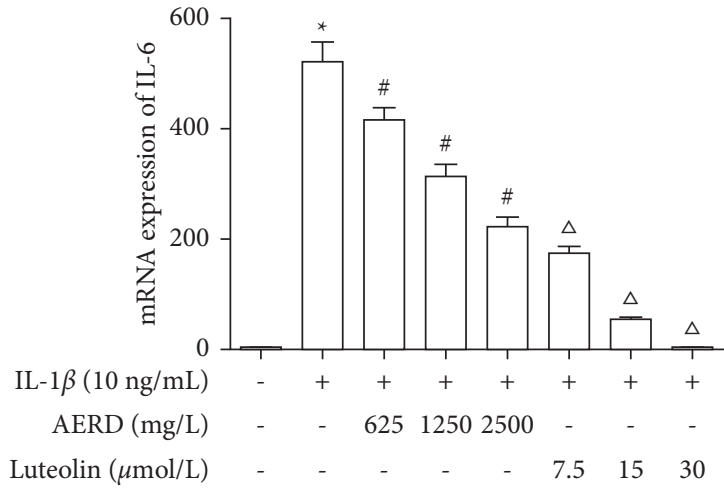

(a)

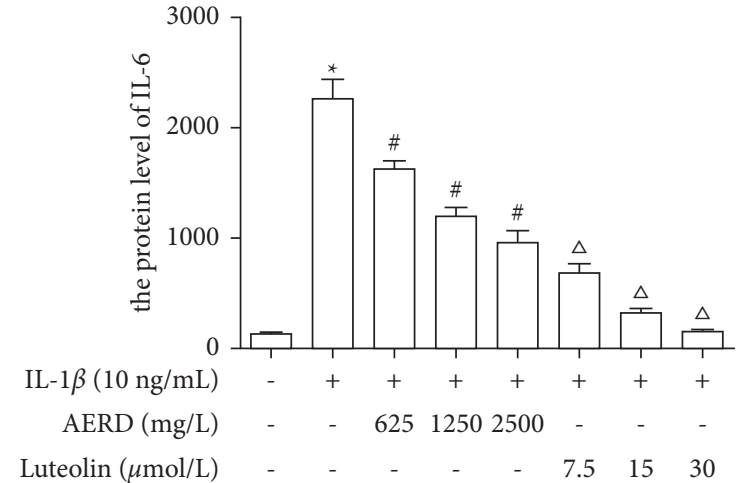

(b)

FIgURE 9: mRNA and protein levels of IL-6 in IL-1 $\beta$-treated SW1353 cells pretreated with the aqueous extract of Rhizoma Drynariae (AERD) or luteolin. SW 1353 cells were pretreated with $625 \mathrm{mg} / \mathrm{L}, 1250 \mathrm{mg} / \mathrm{L}$, or $2500 \mathrm{mg} / \mathrm{L}$ AERD or $7.5 \mu \mathrm{mol} / \mathrm{L}, 15 \mu \mathrm{mol} / \mathrm{L}$, or $30 \mu \mathrm{mol} / \mathrm{L}$ luteolin for $1 \mathrm{~h}$, and then treated with $10 \mathrm{ng} / \mathrm{mL}$ IL- $1 \beta$ for $12 \mathrm{~h}$. (a) mRNA expression of IL- 6 in IL- $1 \beta$-treated SW 1353 cells pretreated with AERD or luteolin. (b) The protein levels of IL-6 in IL-1 $\beta$-treated SW1353 cells pretreated with AERD or luteolin. The data are derived from three independent experiments and expressed as the mean \pm standard deviation $\left({ }^{*} p<0.05\right.$ : increase significantly compared with the control group; $p<0.05$ : decrease with the concentration of AERD compared with the IL- $1 \beta$-treated group; and $p<0.05$ : significance differences between low dose, medium dose, and high dose of luteolin and AERD).

In the study, the PPI network results suggested that IL-6 is the most critical target of Rhizoma Drynariae in the treatment of OA. Therefore, the expression of IL-6 at the mRNA and protein level was selected as the basis for the evaluation of the effect of AERD and luteolin on OA. In vitro experiments showed that the pretreatment of AERD or luteolin can exhibit a significant inhibitory effect on IL-6 expression and show a dose-dependent effect. The inhibitory effect of luteolin on IL-6 was more significant than that of $\mathrm{AERD}$, and the maximum concentration of luteolin restored IL-6 to the normal level.

The pathways predicted by KEGG were further analyzed in combination with the literature. The PI3K/AKT signaling pathway is highly correlated with many pathological conditions, such as cell proliferation [28], cell differentiation [29], cell apoptosis [30], cell autophagy [31], and inflammatory response [32]. Numerous studies have confirmed that aberrant activation of the PI3K/AKT signaling pathway has been implicated in tumorigenesis and migration [33], diabetes [34], atherosclerosis [35], and rheumatoid arthritis [36]. After stimulation by related inflammatory factors, PI3K is activated, which is accompanied by molecular conformational changes that trigger the phosphorylation of AKT. Phosphorylated AKT can further lead to the polyubiquitination and proteasomal degradation of I $\kappa \mathrm{B}-\alpha$ in the cytoplasm, which results in the translocation of NF- $\kappa \mathrm{B}$ p65 into the nucleus and promotes the transcription of IL-6, TNF- $\alpha$, IL-17, Bax, and HIF- $1 \alpha$. TNF- $\alpha$, IL-17, and HIF- $1 \alpha$ can activate TNF, IL-17, and HIF pathways, respectively [37, 38]. Bcl2 and Bax can regulate apoptotic pathways [39]. Thus, the PI3K/AKT signaling pathway can modulate TNF, IL-17, and HIF and apoptotic pathways by its regulatory effect on the NF- $\kappa \mathrm{B}$ signaling pathway. 


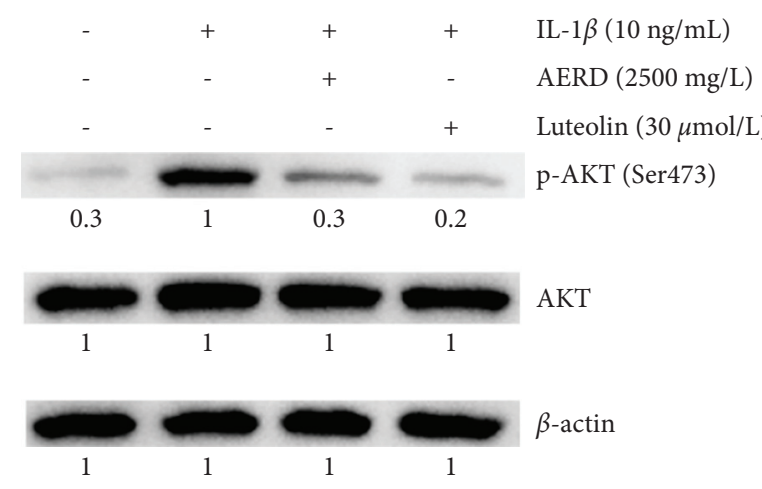

(a)

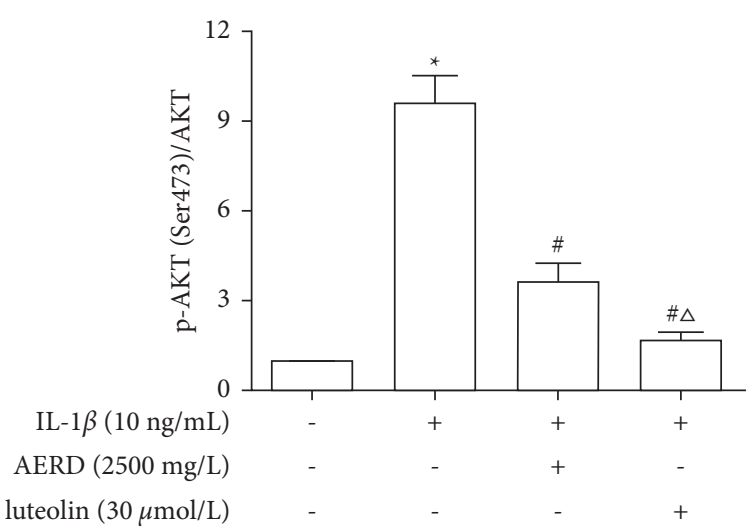

(b)

FIGURE 10: p-AKT levels in IL-1 $\beta$-treated SW1353 cells pretreated with the aqueous extract of Rhizoma Drynariae (AERD) or luteolin. SW1353 cells were pretreated with $2500 \mathrm{mg} / \mathrm{L}$ AERD or $30 \mu \mathrm{mol} / \mathrm{L}$ luteolin for $1 \mathrm{~h}$ and then treated with $10 \mathrm{ng} / \mathrm{mL} \mathrm{IL}-1 \beta$ for $12 \mathrm{~h}$. p-AKT (Ser473)/AKT levels were measured by western blotting. The data are derived from three independent experiments and expressed as mean \pm standard deviation $\left({ }^{*} p<0.05\right.$ : increased when compared with the control group; $p<0.05$ : decreased when compared with the IL- $1 \beta$ treated group; and $p<0.05$ : decreased when compared with the AERD-treated group).

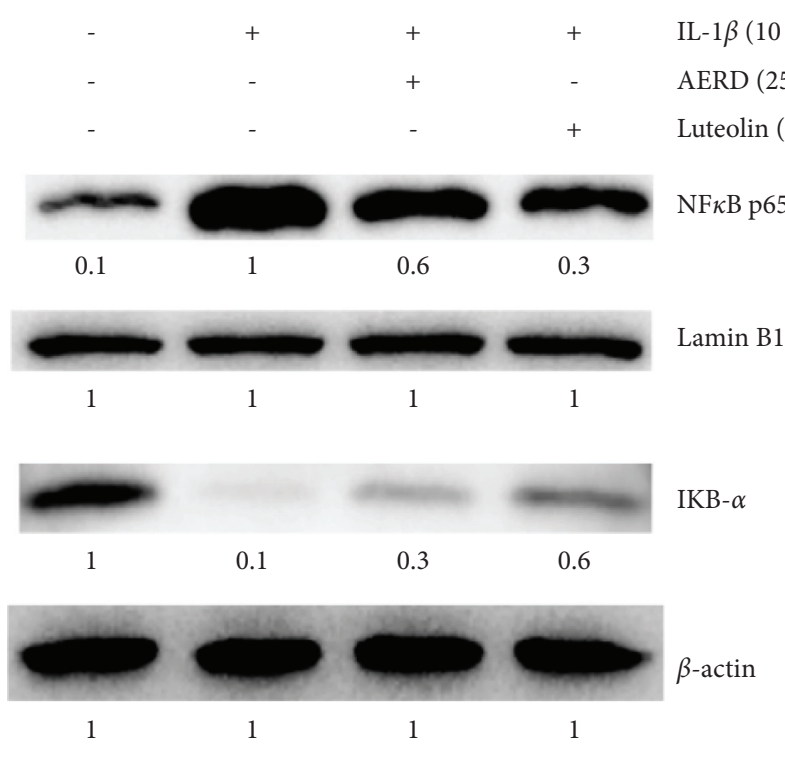

(a)
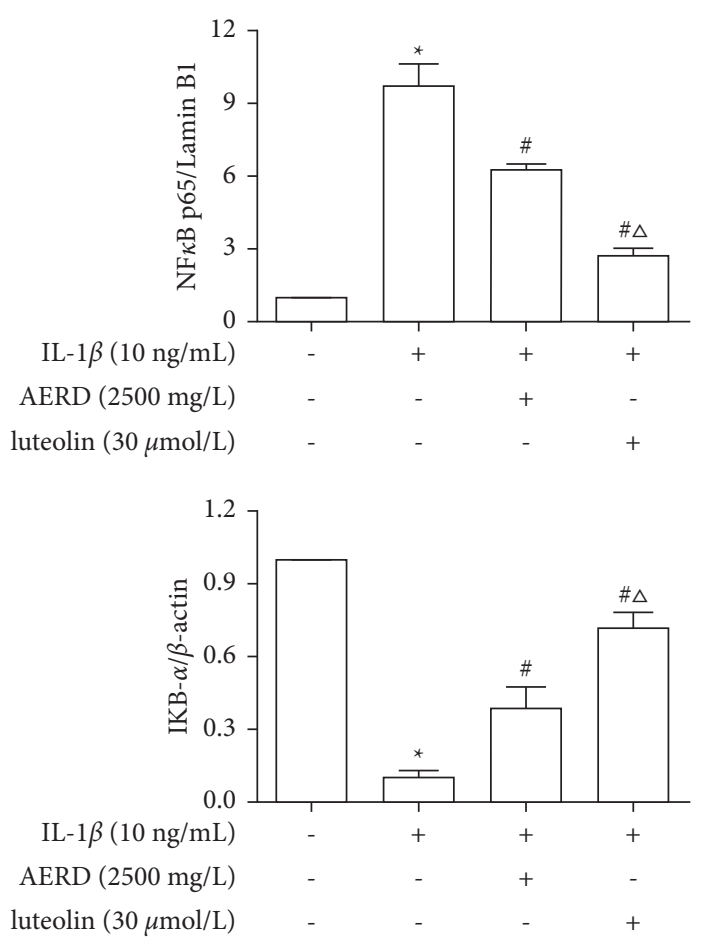

(b)

Figure 11: NF- $\kappa$ B p65 and I $\kappa$ B- $\alpha$ levels in IL- $1 \beta$-treated SW1353 cells pretreated with the aqueous extract of Rhizoma Drynariae (AERD) and luteolin. SW 1353 cells were pretreated with $2500 \mathrm{mg} / \mathrm{L}$ AERD or $30 \mu \mathrm{mol} / \mathrm{L}$ luteolin for $1 \mathrm{~h}$ and then treated with $10 \mathrm{ng} / \mathrm{mL}$ IL- $1 \beta$ for $30 \mathrm{~min}$. The I $\kappa \mathrm{B}-\alpha$ level in the cytoplasm and the NF- $\kappa \mathrm{B}$ p65 level in the nucleus were measured by western blotting. Lamin B and $\beta$-actin were used as internal references for the nuclear and cytoplasmic fractions, respectively. The data are derived from three independent experiments and expressed as the mean \pm standard deviation $\left({ }^{*} p<0.05\right.$ : increased when compared to the control group; ${ }^{\#} p<0.05$ : decreased when compared to the IL- $1 \beta$-treated group; and $p<0.05$ : decreased when compared with the AERD-treated group).

It is found that, after IL- $1 \beta$ stimulation, the phosphorylated AKT of SW1353 cells decreases in $\mathrm{I} \kappa \mathrm{B}-\alpha$ in the cytoplasm and increases in $\mathrm{NF}-\kappa \mathrm{B}$ p65 in the nucleus, suggesting the abnormal activation of the PI3K/AKT/NF- $\kappa \mathrm{B}$ signaling pathway. Simultaneously, the elevation of HIF-1 $\alpha$ at the mRNA level suggests that IL- $1 \beta$ may activate the HIF$1 \alpha$ pathway via promoting the synthesis of HIF- $1 \alpha$. After we stimulated the cells with LPS (an inflammatory stimulator which is more intense than IL-1 $\beta$ ), the mitochondrial membrane potential $(\Delta \psi \mathrm{m})$ fell, which is the sign of cell early 

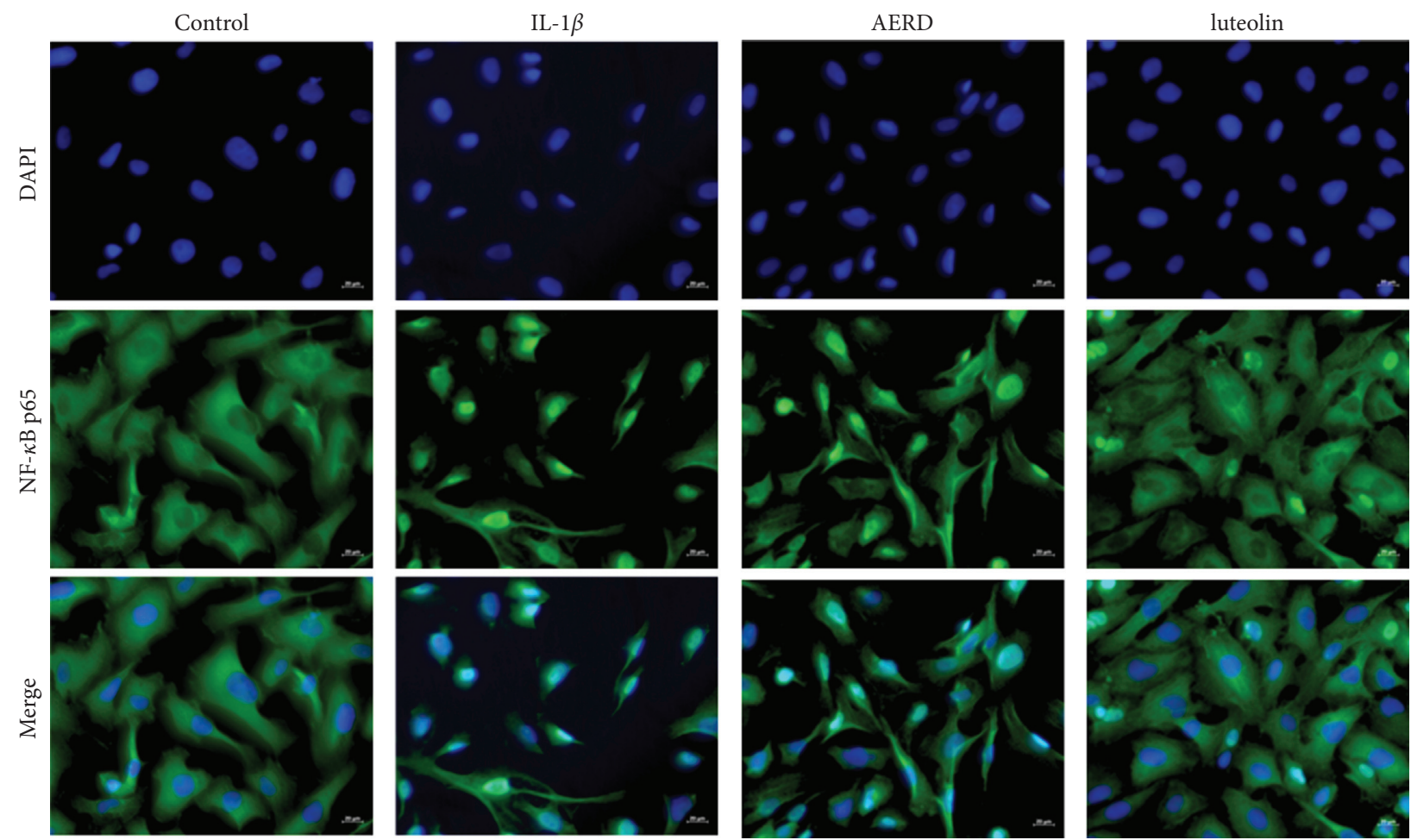

FIgURE 12: The cells were pretreated with the aqueous extract of Rhizoma Drynariae (AERD) or luteolin for $1 \mathrm{~h}$ before IL- $1 \beta$ treatment $(10 \mathrm{ng} / \mathrm{ml})$. After $30 \mathrm{~min}$ of the intervention of IL- $1 \beta$, the localization of NF- $\kappa$ B p 65 was visualized with immunofluorescence by fluorescence microscopy after being marked with an anti-NF- $\kappa \mathrm{B}$ p65 antibody (green). The cells were also marked with DAPI to visualize the nuclei (blue).

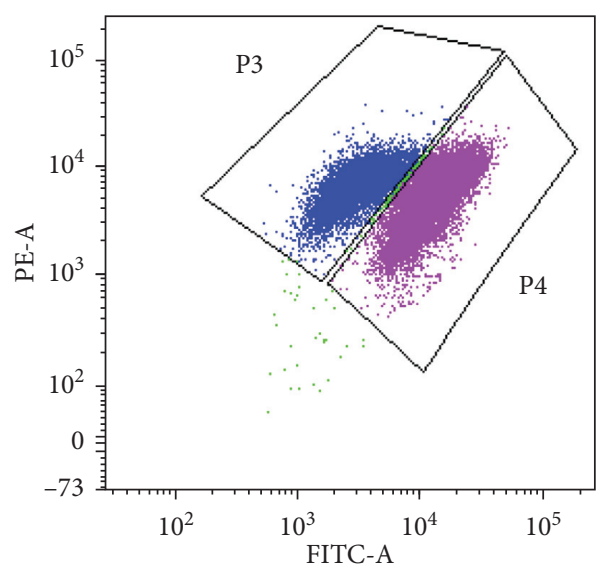

(a)

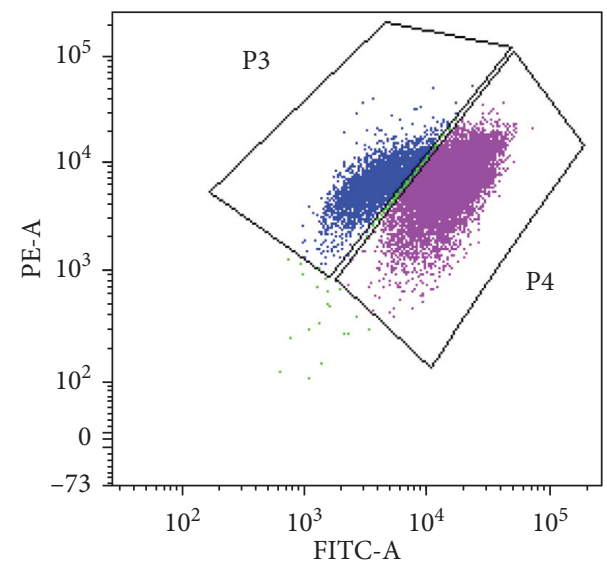

(b)

Figure 13: Continued. 


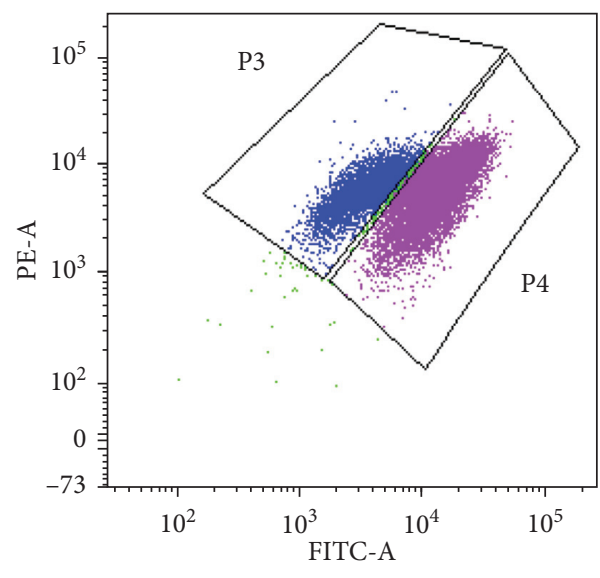

(c)

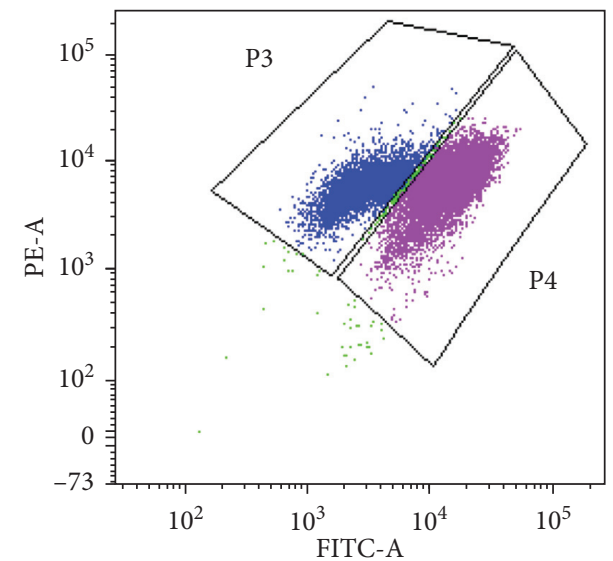

(d)

FIGURE 13: The cells were pretreated with the aqueous extract of Rhizoma Drynariae (AERD) or luteolin for $1 \mathrm{~h}$ before LPS stimulation. After $24 \mathrm{~h}$ of incubation, flow cytometry was performed to measure the red/green JC-1 fluorescence. P3 represents the green JC-1 fluorescence of cells, and P4 represents the red JC-1 fluorescence of cells. The groups are as follows: (a) the control group; (b) LPS-treated group; (c) AERDtreated group; and (d) luteolin-treated group.

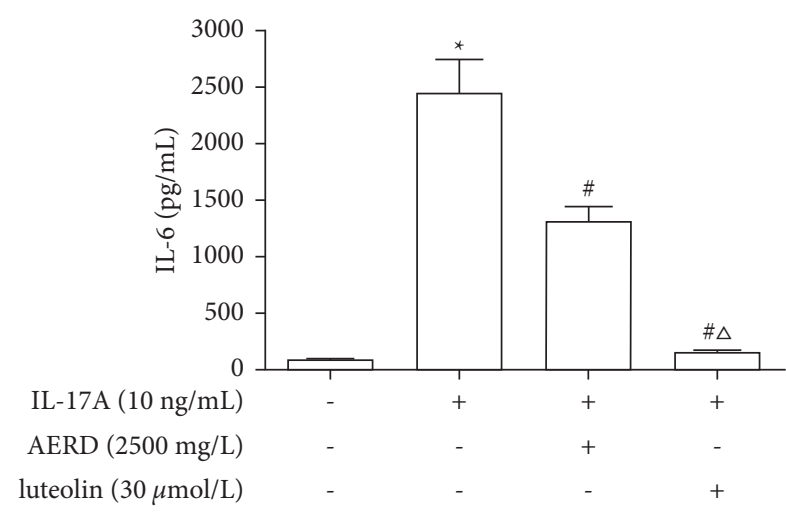

(a)

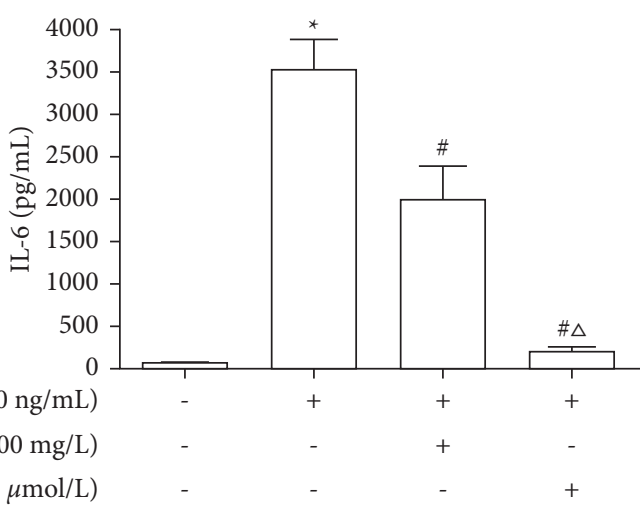

(b)

Figure 14: The content of IL-6 in the culture supernatants of IL-17A or TNF- $\alpha$-treated SW1353 cells pretreated with the aqueous extract of Rhizoma Drynariae (AERD) or luteolin. SW1353 cells were pretreated with $2500 \mathrm{mg} / \mathrm{L}$ AERD or $30 \mu \mathrm{mol} / \mathrm{L}$ luteolin for $1 \mathrm{~h}$ and then treated with $10 \mathrm{ng} / \mathrm{mL}$ IL-17A or TNF- $\alpha$ for $12 \mathrm{~h}$. (a) The content of IL-6 in the culture supernatant of IL-17A-treated SW1353 cells pretreated with AERD or luteolin. (b) The content of IL-6 in the culture supernatant of TNF- $\alpha$-treated SW1353 cells pretreated with AERD or luteolin. The data are derived from three independent experiments and expressed as the mean \pm standard deviation $\left({ }^{*} p<0.05\right.$ : increased when compared to the control group; ${ }^{\#} p<0.05$ : decreased when compared to the cytokines-treated group; and ${ }^{\triangle} p<0.05$ : decreased when compared with the AERD-treated group).

apoptosis [40]. As two significant proinflammatory cytokines, IL-17A and TNF- $\alpha$ can activate IL-17 and TNF pathways, respectively, resulting in abundant secretion of inflammatory factors, such as IL-6. The pretreatment of
AERD or luteolin can reverse these changes to a certain extent, and luteolin had a more significant effect.

In conclusion, luteolin is the most critical component of Rhizoma Drynariae in the treatment of OA, whose 


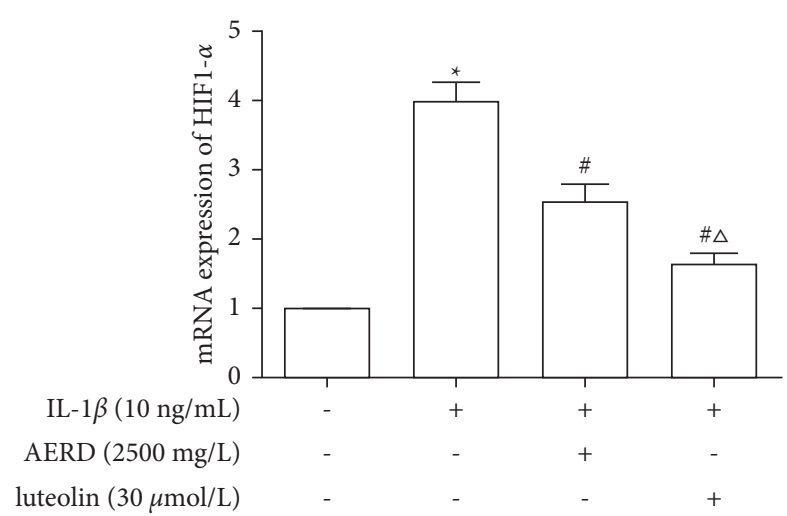

FIgURE 15: mRNA levels of HIF- $1 \alpha$ and TNF- $\alpha$ in IL- $1 \beta$-treated SW1353 cells pretreated with the aqueous extract of Rhizoma Drynariae (AERD) or luteolin. SW1353 cells were pretreated with $2500 \mathrm{mg} / \mathrm{L} \mathrm{AERD}$ or $30 \mu \mathrm{mol} / \mathrm{L}$ luteolin for $1 \mathrm{~h}$ and then treated with $10 \mathrm{ng} / \mathrm{mL}$ IL- $1 \beta$ for $12 \mathrm{~h}$. (a) mRNA expression of HIF- $1 \alpha$ in IL- $1 \beta$-treated SW 1353 cells pretreated with AERD or luteolin. (b) mRNA expression of TNF- $\alpha$ in IL- $1 \beta$-treated SW1353 cells pretreated with AERD or luteolin. The data are derived from three independent experiments and expressed as mean \pm standard deviation $\left({ }^{*} p<0.05\right.$ : increase compared to the control group; ${ }^{\#} p<0.05$ : decrease compared to the IL- $1 \beta$-treated group; and ${ }^{\triangle} p<0.05$ : decrease compared with the AERD-treated group).

mechanism may be strongly associated with its inhibitory effect on IL-6 expression via the PI3K/AKT/NF- $\kappa \mathrm{B}$ pathway and their regulatory role on their downstream signaling pathways. The inadequacy of our study is that the therapeutic effects and mechanism of Rhizoma Drynariae and the key component luteolin on OA were only verified through in vitro experiments. These results should be further validated by in vivo experiments.

\section{Data Availability}

The data used to support the findings of this study are available from the corresponding author upon reasonable request.

\section{Conflicts of Interest}

The authors declare that they have no conflicts of interest.

\section{Authors' Contributions}

Guang-yao Chen and Xiao-yu Liu contributed equally to this work.

\section{Supplementary Materials}

Supplementary Table 1. Detailed information on putative targets. Supplementary Table 2. Detailed information on known OA-related genes. (Supplementary Materials)

\section{References}

[1] J. W. Bijlsma, F. Berenbaum, and F. P. Lafeber, "Osteoarthritis: an update with relevance for clinical practice," The Lancet, vol. 377, no. 9783, pp. 2115-2126, 2011.
[2] D. T. Felson, A. Naimark, J. Anderson, L. Kazis, W. Castelli, and R. F. Meenan, "The prevalence of knee osteoarthritis in the elderly. The Framingham Osteoarthritis Study," Arthritis \& Rheumatism, vol. 30, no. 8, pp. 914-918, 1987.

[3] A. Lanas, L. A. Garcia-Rodriguez, M. T. Arroyo et al., "Risk of upper gastrointestinal ulcer bleeding associated with selective cyclo-oxygenase- 2 inhibitors, traditional non-aspirin nonsteroidal anti-inflammatory drugs, aspirin and combinations," Gut, vol. 55, no. 12, pp. 1731-1738, 2006.

[4] S. Toegel, S. Q. Wu, C. Piana et al., "Comparison between chondroprotective effects of glucosamine, curcumin, and diacerein in IL- $1 \beta$-stimulated C-28/I2 chondrocytes," Osteoarthritis and Cartilage, vol. 16, no. 10, pp. 1205-1212, 2008.

[5] T. McAlindon, M. Formica, M. LaValley, M. Lehmer, and K. Kabbara, "Effectiveness of glucosamine for symptoms of knee osteoarthritis: results from an internet-based randomized double-blind controlled trial," The American Journal of Medicine, vol. 117, no. 9, pp. 643-649, 2004.

[6] Y.-H. Kang, H. J. Lee, C. J. Lee, and J.-S. Park, "Natural products as sources of novel drug candidates for the pharmacological management of osteoarthritis: a narrative review," Biomolecules \& Therapeutics, vol. 27, no. 6, pp. 503-513, 2019.

[7] Y. Zhang, J. Jiang, H. Shen, Y. Chai, X. Wei, and Y. Xie, “Total flavonoids from Rhizoma Drynariae (Gusuibu) for treating osteoporotic fractures: implication in clinical practice," Drug Design, Development and Therapy, vol. 11, pp. 1881-1890, 2017.

[8] Q.-W. Tao, Y. Xu, D.-E. Jin, and X.-P. Yan, "Clinical efficacy and safety of Gubitong Recipe (骨㿎通方) in treating osteoarthritis of knee joint," Chinese Journal of Integrative Medicine, vol. 15, no. 6, pp. 458-461, 2009.

[9] A. L. Hopkins, "Network pharmacology: the next paradigm in drug discovery," Nature Chemical Biology, vol. 4, no. 11, pp. 682-690, 2008.

[10] D. He, J.-H. Huang, Z.-Y. Zhang et al., "A network pharmacology-based strategy for predicting active ingredients and potential targets of LiuWei DiHuang pill in treating type 2 diabetes mellitus," Drug Design, Development and Therapy, vol. 13, pp. 3989-4005, 2019.

[11] G.-Y. Chen, J.-Q. Chen, X.-Y. Liu et al., "Total flavonoids of rhizoma Drynariae restore the MMP/TIMP balance in models of osteoarthritis by inhibiting the activation of the NF- $\kappa \mathrm{B}$ and PI3K/AKT pathways," Evidence-based Complementary and Alternative Medicine, vol. 2021, Article ID 6634837, 14 pages, 2021.

[12] K. Sun, J. Luo, J. Guo, X. Yao, X. Jing, and F. Guo, "The PI3K/ AKT/mTOR signaling pathway in osteoarthritis: a narrative review," Osteoarthritis and Cartilage, vol. 28, no. 4, pp. 400-409, 2020.

[13] Y. Zhao, Y. Li, R. Qu et al., "Cortistatin binds to TNF- $\alpha$ receptors and protects against osteoarthritis," EBioMedicine, vol. 41, pp. 556-570, 2019.

[14] H. J. Faust, H. Zhang, J. Han et al., "IL-17 and immunologically induced senescence regulate response to injury in osteoarthritis," Journal of Clinical Investigation, vol. 130, no. 10, pp. 5493-5507, 2020.

[15] H. Hwang and H. Kim, "Chondrocyte apoptosis in the pathogenesis of osteoarthritis," International Journal of Molecular Sciences, vol. 16, no. 11, pp. 26035-26054, 2015.

[16] S. Hu, C. Zhang, L. Ni et al., "Stabilization of HIF- $1 \alpha$ alleviates osteoarthritis via enhancing mitophagy," Cell Death \& Disease, vol. 11, no. 6, p. 481, 2020. 
[17] M. V. Smith, M. J. Lee, A. S. Islam et al., "Inhibition of the PI3K-akt signaling pathway reduces tumor necrosis factor- $\alpha$ production in response to titanium particles in vitro," The Journal of Bone and Joint Surgery, vol. 89, no. 5, pp. 10191027, 2007.

[18] F. He, H. Liu, and W. Luo, "The PI3K-Akt-HIF-1 $\alpha$ pathway reducing nasal airway inflammation and remodeling in nasal polyposis," Ear, Nose, \& Throat Journal, vol. 100, 2021.

[19] B. Wang, C.-H. Zhao, G. Sun et al., "IL-17 induces the proliferation and migration of glioma cells through the activation of PI3K/Akt1/NF- $\kappa$ B-p65," Cancer Letters, vol. 447, pp. 93-104, 2019.

[20] H. Tao, L. Cheng, and R. Yang, "Downregulation of miR-34a promotes proliferation and inhibits apoptosis of rat osteoarthritic cartilage cells by activating PI3K/akt pathway," Clinical Interventions in Aging, vol. 15, pp. 373-385, 2020.

[21] W. H. Robinson, C. M. Lepus, Q. Wang et al., "Low-grade inflammation as a key mediator of the pathogenesis of osteoarthritis," Nature Reviews Rheumatology, vol. 12, no. 10, pp. 580-592, 2016.

[22] T. Kishimoto, "IL-6: from its discovery to clinical applications," International Immunology, vol. 22, no. 5, pp. 347-352, 2010.

[23] T. Tanaka, M. Narazaki, K. Masuda, and T. Kishimoto, "Regulation of IL-6 in immunity and diseases," Advances in Experimental Medicine \& Biology, vol. 941, pp. 79-88, 2016.

[24] S. W. Cho, F. Q. Pirih, A. J. Koh et al., "The soluble interleukin-6 receptor is a mediator of hematopoietic and skeletal actions of parathyroid hormone," Journal of Biological Chemistry, vol. 288, no. 10, pp. 6814-6825, 2013.

[25] E. Y. Ting, A. C. Yang, and S. J. Tsai, "Role of interleukin-6 in depressive disorder," International Journal of Molecular Sciences, vol. 21, 2020.

[26] M. Laavola, T. Leppänen, M. Hämäläinen et al., "IL-6 in osteoarthritis: effects of pine stilbenoids," Molecules, vol. 24, 2018.

[27] Y. Lin, L. Liu, H. Jiang, J. Zhou, and Y. Tang, "Inhibition of interleukin- 6 function attenuates the central sensitization and pain behavior induced by osteoarthritis," European Journal of Pharmacology, vol. 811, pp. 260-267, 2017.

[28] J. S. L. Yu and W. Cui, "Proliferation, survival and metabolism: the role of $\mathrm{PI} 3 \mathrm{~K} / \mathrm{AKT} / \mathrm{mTOR}$ signalling in pluripotency and cell fate determination," Development, vol. 143, no. 17, pp. 3050-3060, 2016.

[29] C. Song, Z. Yang, D. Dong et al., "miR-483 inhibits bovine myoblast cell proliferation and differentiation via IGF1/PI3K/ AKT signal pathway," Journal of Cellular Physiology, vol. 234, no. 6, pp. 9839-9848, 2019.

[30] J. Yang, C. Pi, and G. Wang, "Inhibition of PI3K/Akt/mTOR pathway by apigenin induces apoptosis and autophagy in hepatocellular carcinoma cells," Biomedicine \& Pharmacotherapy, vol. 103, pp. 699-707, 2018.

[31] Z. Xu, X. Han, D. Ou et al., "Targeting PI3K/AKT/mTORmediated autophagy for tumor therapy," Applied Microbiology and Biotechnology, vol. 104, no. 2, pp. 575-587, 2020.

[32] J.-F. Xue, Z.-M. Shi, J. Zou, and X.-L. Li, "Inhibition of PI3K/ $\mathrm{AKT} / \mathrm{mTOR}$ signaling pathway promotes autophagy of articular chondrocytes and attenuates inflammatory response in rats with osteoarthritis," Biomedicine \& Pharmacotherapy, vol. 89, pp. 1252-1261, 2017.

[33] H. Chen, L. Zhou, X. Wu et al., "The PI3K/AKT pathway in the pathogenesis of prostate cancer," Frontiers in Bioscience, vol. 21, pp. 1084-1091, 2016.
[34] X. Huang, G. Liu, J. Guo, and Z. Su, "The PI3K/AKT pathway in obesity and type 2 diabetes," International Journal of Biological Sciences, vol. 14, no. 11, pp. 1483-1496, 2018.

[35] M. F. Linton, J. J. Moslehi, and V. R. Babaev, "Akt signaling in macrophage polarization, survival, and atherosclerosis," International Journal of Molecular Sciences, vol. 20, 2019.

[36] K. Chen, Z.-W. Lin, S.-M. He et al., "Metformin inhibits the proliferation of rheumatoid arthritis fibroblast-like synoviocytes through IGF-IR/PI3K/AKT/m-TOR pathway," Biomedicine \& Pharmacotherapy, vol. 115, Article ID 108875, 2019.

[37] N. Romero, C. Van Waesberghe, and H. W. Favoreel, "Pseudorabies virus infection of epithelial cells leads to persistent but aberrant activation of the NF- $\kappa$ B pathway, inhibiting hallmark NF- $\kappa \mathrm{B}$-Induced proinflammatory gene expression," Journal of Virology, vol. 94, Article ID e00196-20, 2020.

[38] M. Mussbacher, M. Salzmann, C. Brostjan et al., "Cell typespecific roles of NF- $\kappa$ B linking inflammation and thrombosis," Frontiers in Immunology, vol. 10, p. 85, 2019.

[39] J. Cui and W. Placzek, "Post-transcriptional regulation of anti-apoptotic BCL2 family members," International Journal of Molecular Sciences, vol. 19, no. 1, p. 308, 2018.

[40] T. T. T. Nguyen, C. T. Ishida, E. Shang et al., "Activation of $\operatorname{LXR} \beta$ inhibits tumor respiration and is synthetically lethal with Bcl-xL inhibition," EMBO Molecular Medicine, vol. 11, Article ID e10769, 2019. 